\title{
Neonatal Eye Defects and Stem Cell Therapeutics
}

\author{
Review Article
}

Upadhyay RK

Department of Zoology, D D U Gorakhpur University, Gorakhpur, UP, India.

\section{Abstract}

Present review aims to describe various neonatal eye defects and its stem cell therapeutics. This article attempts to highlight common causes of visual impairment in infants and present the recent approaches used for restoration of normal vision in patients. The article highlights the need for setting microenvironment or stem cell micro niche for regeneration of opticneural complexes. Till date no proven drug based treatment existed for inherited eye defects. By adopting different therapeutic measures causal effects can be improved. The article advocates cell based therapeutics for wound healing of optical tissues for functional restoration using appropriate and suitable cell transplantations in animal models. In addition, possible solutions have been suggested to reduce the pain in newborns and infants from serious life-threatening visual complications or infection induced visual pathogenesis. This article emphasizes use of stem cell derived lens cells for human lens development and regeneration of corneal and retinal cells for increasing future therapeutic applications. As an alternative remedy exploring and designing new biomaterials to make matrix based nano-structure constructs for corneal repair and regeneration has been suggested. Bioengineered corneal devices are addressed with safe use of tissue-engineered hydrogels to allow regeneration of radiosensitivity in neural-visual cell complex. Present review presents new advancements in the field of biocompatible substrates, bio-matrix, transplantation methods and micro-niche maintaining factors for restoration, repairing and healing of visual-neuroepithelial complexes successfully.

Keywords: Neonatal Eye Defects; Corneal and Stromal Cells; Limbal Stem Cell Deficiency; Biomaterials; Transplantations.

\section{Introduction}

A large percentage of infants (early age) face congenital visual impairments that persist throughout adult life and remain uncurable. Most common neonatal eye defects at global level are related to structure and function of cornea, lens, retina, optic nerve and visual cortex in the brain. Approximately more than 300 million people bear congiental defects and suffer from various eye diseases such as cataracts, glaucoma, age-related macular degeneration, diabetic retinopathy, and corneal diseases. Out of these, roughly 10 million people suffer from severe ocular surface diseases. Such cases are reported from developing countries only. Vision incapacitation, blindness and retinal degeneration, glaucoma, macular degeneration, and retinitis pigmentosa, cataracts, aneurosis, ageoptic neuritis, retinitis pigmentosa, strabismus are important neonatal eye defects [1]. There are many congenital anomalies such as anophthalmos, microphthalmos, coloboma, congenital cataract, infantile glaucoma, and neuro-ophthalmic lesions which are diagnosed at birth. Other impairments like ophthalmia neonatorum, retinopathy of prematurity and cortical visual impairment are acquired during the perinatal period. Leukocoria or white pupillary reflex can be caused by congenital cataract, persistent hyperplastic primary vitreous, or retinoblastoma. Retinal haemorrhage [2] and spontaneous corneal perforation are also noted in neonates [3] (Table 1) (Figure 2).

Most of the congenital disorders originate during embryonic development due to adverse effect of environmental mutagenes, drugs, and gene mutations. Few of them could be partially restored by using stem cell transplantation therapy but most of mechanical-physical-physiological defects give rise to permanent defects/impairments and remain non restorable. Few congenital eye malformations are curable but replacement of any part of eye is too difficult to obtain a suitable transplant. Eye functions like a photographic camera wherein replacement of any component of camera is easy, but is very difficult in case of eye a visual photoreceptor. Any physiological and structural impairment in one or more eye component obstructs its normal function (Figure 1). Normally an electronic part of a camera could be replaced, but a

\section{*Corresponding Author:}

Ravi Kant Upadhyay,

Department of Zoology, D D U Gorakhpur University, Gorakhpur, 273009, UP, India

Email: rkupadhya@yahoo.com

Received: July 07, 2016

Accepted: August 23, 2016

Published: August 26, 2016

Citation: Upadhyay RK (2016) Neonatal Eye Defects and its Stem Cell Therapeutics. Int J Stem Cell Res Transplant. 04(6), 195-215. doi: http://dx.doi.org/10.19070/2328-3548-1600032

Copyright: Upadhyay $\mathbf{R K}^{\circ}$ 2016. This is an open-access article distributed under the terms of the Creative Commons Attribution License, which permits unrestricted use, distribution and reproduction in any medium, provided the original author and source are credited. 
new biological component of the eye is not easy to replace (transplantation).

Dry eye syndrome (DES) is one of the most common ocular diseases that represent impaired vision or even blindness in neonates and adult children. Few neonatal eye defects are highly complicated and persist lifelong and remain untreatable. Best example is Joubert syndrome and related disorders which are caused due to complex midbrain-hindbrain malformation [4]. There are few rare defects such as Ankyloblepharon-ectodermal dysplasia-clefting (AEC) [5] (Table 1), persistent fetal vasculature [6], nasolacrimal duct obstruction [7], hypomyelination, congenital cataract (HCC), and neonatal corneal opacities (NCO) are most common visual impairments noted in infants [8] (Figure 2). Oculo-auriculo-vertebral spectrum is a complex developmental disorder that perpetuates defects in ear, hemifacial microsomia, epibulbar dermoids and vertebral anomalies. Other neonatal diseases like popliteal pterygia, syngnathia, cleft lip and palate, retrognathia and popliteal pterygium syndrome (PPS) are also rare defects found in infants [9]. Gene mutation causes severe physiological diseases like respiratory distress, including tachypnea, nasal flaring, grunting, retractions, cyanosis, and craniosynostosis in infants [10]. Congenital microphthalmia is a rare disorder shows defects in primary optic vesicle [11]. (Table 1) (Figure 2).

At global level important congenital eye defects i.e. anophthalamos, congenital cystic eye, coloboma, nanophthalmos and microphthalmos are recorded. There are certain defects of eye lid such as congenital ptosis, eyelid coloboma, and cryptophthalmos. There are certain defects of eye lid such as congenital ptosis, eyelid coloboma, Cryptophthalmos; cornea i.e. congenital glaucoma (most common with an abnormally large eye), endothelial development abnormalities, Persistent attachment of lens, intrauterine inflammation, interstitial keratitis, megalocornea. Defects of iris and pupil are corectopia, polycoria, and coloboma of iris, aniridia, and albinism, heterochromia while defects of lens are congenital cataracts, glaucoma and anisometropia. Other lens and anterior segment defects, vitrous defects are also observed such as leukocoria and severe posterior uveitis/vitritis. Defects of choroid and retina, central coloboma of the disc, optic nerve hypoplasia and few extra ocular defects such as dermoids, conjunctivitis and dacryocystitis, craniofacial anomalies are also seen. There are also problems of poor vision with no apparent cause. Congenital glaucoma is often bilateral and associated with other defects. It is the most common non-syndromic glaucoma in infancy. The most characteristic ocular findings associated with congenital infection are chorioretinal scars and chorioretinitis. Genetic disorders are a leading cause of visual impairment in children. They include anophthalmia, aniridia, albinism, anterior segment dysgenesis, Marfan's syndrome, ectopia lentis, neurofibromatosis, retinal hemangioblastomas and familial exudative vitreoretinopathy.

Neonatal progeroid syndrome (NPS) and Pierson syndrome are rare autosomal recessive disorders which are related with diverse defects. NPS implies effects like bilateral upper eyelid entropion and stromal keratitis [12] (Table 1) while Pierson syndrome is re-

Figure 1. Eye is a complex organ made up of layers of different cell types.

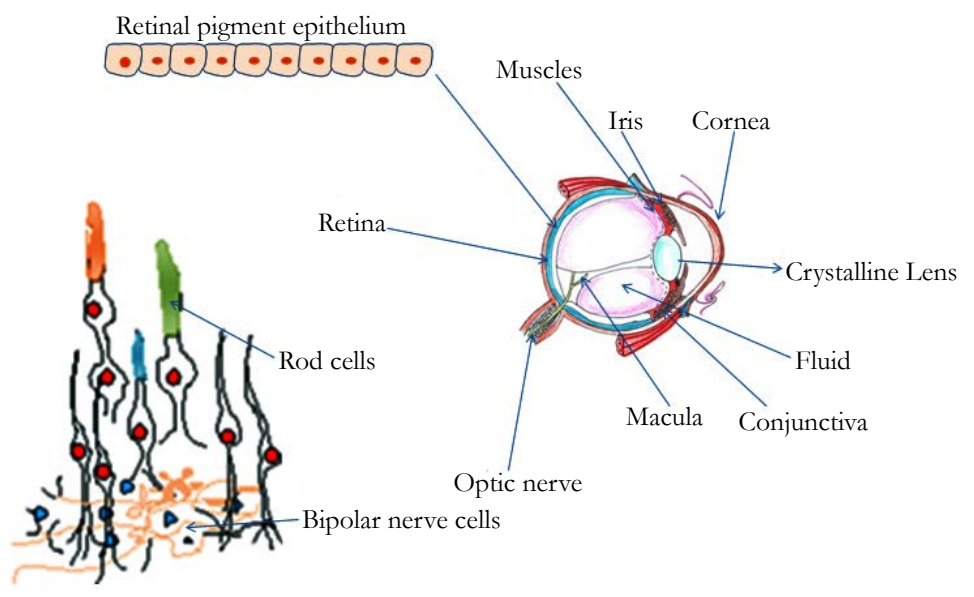

Figure 2. Showing various neonatal eye diseases which causes visual impairment in new born and infants.

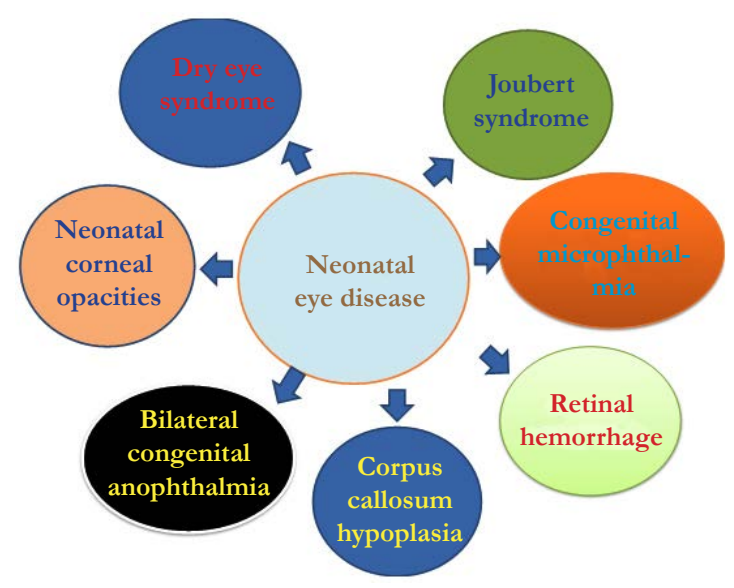


lated to congenital nephritic defects, diffuse mesangial sclerosis, microcoria and retinal haemorrhages [13]. Disease like incontinentia pigmenti is a rare X-linked multisystem disorder that implies periventricular and subcortical white matter problems, haemorrhagic changes, corpus callosum hypoplasia, cerebral atrophy and cerebellar hypoplasia [14]. Few disorders like Alexander disease and mitochondrial leukoencephalopathies show myriad of symptoms and signs which perist from neonatal age to adulthood. Both diseases display white matter changes, signaling defects of basal ganglia or thalami and brainstem [15]. Oculo-auricular syndrome (OAS) in humans is caused due to mutation at HMX1 locus [16]. Ectrodactyly-ectodermal-dysplasia-cleft-syndrome results in vision loss and complete ophthalmic shutdown in early age pateints [17] (Table 1).

Common neonatal eye defects are bilateral congenital cataract [18], embryonic retina regress [19], nystagmus, opticus atrophy, and strabismus [20] and glaucoma [21]. Loss of corneal transparency is also seen in infants at birth or soon after $<4$ weeks of birth [22] while blindness in premature babies is observed due to microphthalmia and cataract formation [23]. Few neonatal structural eye defects (ocular) such as loss of neurons in the retinal ganglion cell (RGC) layer, optic nerve hypoplasia, dysmyelination, and disturbance in retinal cell morphology are generated due to fetal alcohol syndrome [24]. Retinal degeneration is another example of eye related illnesses that imposes severe retinal edema with subretinal fluid bilateral congenital anophthalmia [25] (Figure 2). New borns and infants also develop serious life-threatening complications due to an accidental brain injury [26]. These lead to visual impairments like degeneration of optic nerve and lack of coordination with central nervous system. Glaucoma results due to increased intra-ocular pressure generated after optic nerve degeneration. Optic nerve injury occurred due to severe trauma and disruption of vascular supply after physical injury results in vision loss. Dry eye and limbal stem cell deficiency are serious optic disorders. Corneal blindness is a visual defect which is found globally (Table 1).

\section{Major Reasons}

Chromosomal aberrations, environmental stress and prenatal drug exposure are the most common causes of neonatal eye defects. Eye defects throughout the world result due to high blood pressure, radiation from screen, temperature, dust, heat and humidity. Many people (particularly children) in developing and underdeveloped countries, suffer from undernutrition and insufficient intake of protein and thus face deficiencies of vitamins and minerals, particularly iodine, iron, vitamin A and zinc. These deficiencies are responsible for raising the risk of chronic diseases, such as eye defects, heart disease and cancers. Genetics also play a decisive role in attributing eye defects including life style changes, domestic and cultural environment. In addition, physical influences such as global warming and ultraviolet radiation (UVR) severly affect functions of eye and impose blindness mainly cataract and trachoma which are two of the commonest causes of the world blindness. Trachoma infection causes blindness and changes patient's behaviour. Another major reason of rapid progression of cataract is ozone layer depletion and greater solar UVR receding on earth and rising global warming. There are many physical and biological causes of cataract formation but high UV radiation is a major attributable cause. However, this can be rectified by cataract surgery. Glaucoma is almost certainly now the second cause of worldwide blindness (approximately 14.5\%). Both primary openangle glaucoma (POAG) and primary angle closure is heritable. Nevertheless, there are important environmental risk factors to be confirmed (Figure 3).

Most of the neonatal eye defects are induced in mother's due to administration of heavy drug dosage during pregnancy. Most suscetptible class that shows very high risk of visual problems, are neonates exposed to opiates (methadone) and/or benzodiazepines in utero [27]. Prolonged exposure of ultraviolet radiation (UVR) from sunlight and therapeutic sources causes ocular tissue damage mainly in corneal surface to the retina. UV radiation also distroys stem cells found on anterior ocular surface and the limbus [28] (Figure 3). Post birth apoptosis occurs in differentiating epithelium leading to the damage of the entire eye [29]. Similarly, congenital virus infections caused by cytomegalovirus (CMV) and rubella virus infection [30] is a major cause of birth defects found in early age children [31]. Retinal hemorrhage is also found in infants due to virus infection and is most commonly found in newborns [2]. Over dosage of drugs and nutrition cause visual impairments in premature infants which are life-threatening [32]. Ethanol reacts with fetal membrane; causes cell lysis, suppress cell proliferation, and induce apoptosis. Ethanol exposure disturbs differentiation of stem cells and expression of corneal epithelial

Figure 3. Showing various neonatal eye diseases caused due to environmental stress and action of different carcinogens.

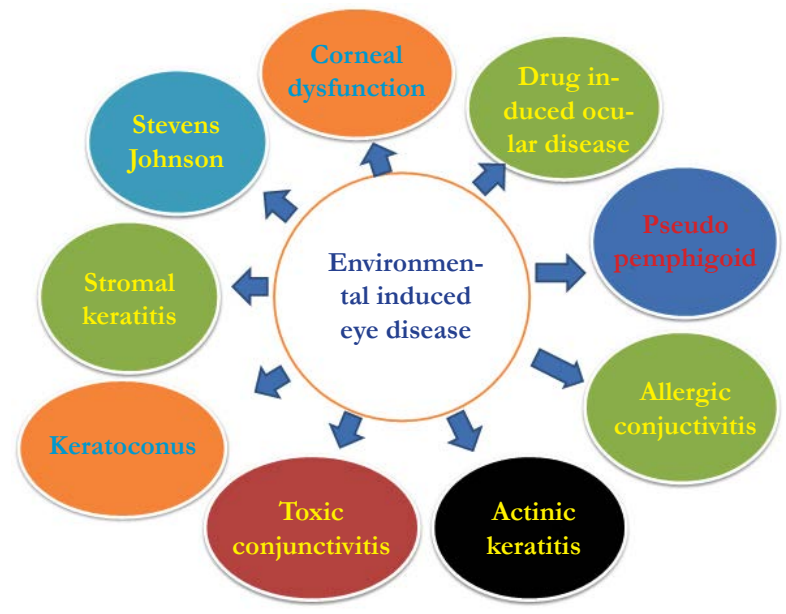


cell-specific markers. Ethanol induces expression of proinflammatory cytokines and chemokines in corneal epithelial and stromal cells [34]. Cystinosis is caused by a deficiency in the lysosomal cystine transporter the cystinosin (CTNS gene) that results in cystine crystal accumulation in tissues mainly in cornea.

As no proven treatment exists for inherited eye defects and only causal effects can be treated/improved by adopting different therapeutic measures. But to avoid lifelong risks an essential ophthalmic examination of neonates should be done by expert pediatricians for early identification of ophthalmic problems. Neonates should pass through red reflex screening test before being discharged from hospital and after attaining an age of 6 weeks [34]. It will lower down the risks related to behavioral abnormalities [35] but sometimes early diagnosis may put critical impact on the prognosis for many ocular conditions, including potentially blinding but cureable defects like congenital cataracts, life-threatening malignancies such as retinoblastoma and harbingers of disease [36]. After seeing the occurrence of sight related disabilities and dysfunctional ophthalmic tissues there is an immense need of neonatal diagnosis to reduce the chances of such problems [4]. There must be an authentic diagnosis based on appropriate and potential biomarkers to treat the neonatal patients having eye defects [37]. In addition, an earlier red reflex screening and physical examination of newborns can short out ophthalmologic abnormality that can reduce mental stress and pain [38].

\section{Development of eye and visual receptors}

Eyes are photoreceptors possess visual pigments which actually provide the basis of photochemical sensation. Eye possesses many vital components which assist to make vision more clear and objects visible. Eye is developed from a pair of optic vesicles situated on each side of forebrain at the end of $4^{\text {th }}$ week of pregnancy. Optic vesciles occur as outgrowths of the brain which make contact with the surface ectoderm from various tissues are derived from three sources i.e. from neuroepithelium, surface ectoderm, and the extracellular mesenchyme which consists of neural crest and mesoderm. Eye components are formed from the wall of diencephalon (neural ectoderm), the superficial ectoderm (epidermal ectoderm), and the mesenchyme (mesoderm) of the head. During its morphogenesis, each of its components parts passes through the phase of induction, and rudiments formation. Its important phases are development, differentiation and growth. Neuroepithelium forms the retina, cilliary body, iris, and optic nerve while extracellular mesenchyme forms the sclera, cornea, blood vessels, muscles, and vitreous. Few important components lens, corneal epithelium and eyelid are also formed. The mammalian eye possess three main layers i.e. the fibrous tunic is the outer layer of the eyeball and consists of cornea and sclera, second middle vascularized or vascular tunic includes the iris, ciliary body and choroid. The choroid contains blood vessels that supply the retinal cells with necessary oxygen and remove the waste of respiration. The inner sensory layer includes the retina. Contributing to vision, the retina contains the photosensitive rod and cone cells and associated neurons. There is an enlarged entire cohort of 14 transcription factors that are required for eye development.

Eye development is initiated by the master control gene Pax-6, a homeobox gene known as Andridia in humans. The Pax-6 gene locus is a transcription factor for the various genes and growth factors involved in eye formation. Hmx1 is a homeodomain transcription factor that is expressed in the developing eye mainly in peripheral ganglia, and branchial arches of avian and mammalian embryos. Different expression patterns of transcription factors and biological signaling are essential step for eye morphogenesis and differentiation. The pattern of expression of genes and transcription factor regulate eye development, proliferation and differentiation of the neuroretina from progenitor cells. These mitotic progenitor cells appear to have the potential to form any of the six major classes of mature neurons i.e. photoreceptors, bipolar, horizontal, interplexiform, amacrine and ganglion cells, as well as Müller cells, a type of glial cell.

The eye morphogenesis starts as an out growth (evagination) of the optic grooves which transform into optic vesicle. The optic vesicles then develop into the optic cup with the inner layer forming the retina and the outer portion forming the retinal pigment epithelium. The hemispheric, bi-layered optic cup is formed from an oval optic vesicle during early vertebrate eye development through major morphological transformations. The middle portion of the optic cup develops into the ciliary body and iris. The prospective neurosecretory retinal layer of optic vesicle inducts the epidermis of head, opposite to the optic vesicles, which thicken to form the lens placodes. The placode of the each side invaginate to form the lens cup which gradually deepens and progressively pinched off from the epidermis, until it form the closed lens vesicles. The component of cornea shows tensile strength and regenerative properties. It displays characteristic interference pattern in polarized light using an appropriate refractive index and a controlled curvature that contributes to its refractory powers and transparency.

The multipotent neuroretinal progenitor cells of the optic cup continue to proliferate and differentiate into mature retinal neurons. The commitment of a competent post-mitotic retinal progenitor cell to a specific cell fate is controlled by signals from the microenvironment. Thus, transcription factors may make post-mitotic retinal cells competent to respond to appropriate environmental stimuli, and initiate the production of signals by the cell that modify the microenvironment, thereby influencing the developmental program of neighbouring cells. Therefore, in a particular environment, the combination of transcription factors expressed by a cell can be regarded as its 'transcription factor code'. Further differentiation and mechanical rearrangement of cells in and around the optic cup gives rise to the fully developed eye.

\section{Eye structure and its components}

Eye of vertebrates possesses a fluid filled globular sac like structure called eye ball. It is structurally complex contains three concentric tunics i.e. fibrous, vascular and neurosensory tunics. Fibrous tunic protects the eye ball that is transparent and forming the cornea. Over the rest of the eye ball it is opaque and called sclerotic coat. The circular line between cornea and sclera is called sclero corneal junction. Histologically, sclera consists of interlacing collagen fibers. In cornea, the collagen fibers are partially arranged in bundles. The external corneal surface is thin and transparent corneal epithelium. The vascular tunic is thinner, middle layer of eye ball consists of three parts i.e. choroid, ciliary body and iris. The large central aperture of iris is called pupil. The third 
coat neurosensory tunic is retina that is innermost, thinnest and softest. The retina is the neurological tissue that lines the inner surface of the eyeball at the back of the eyeball. Retina possess two main layers an outer simple epithelium of cuboidal cells that are heavily pigmented and an inner layer. It is also a simple cuboidal epithelium in ciliary and iris parts of retina but in optic region it is thick and highly complex, containing light sensitive elements, nerve cells and fibres. It consists of three layers an outer layer of rods and cone cells, middle layer of bipolar nerve cells and inner layer of ganglionic nerve cells. The layer of rods and cones consists of highly specialized neurosensory cells which are actual light sensitive cells. The cells of pigment epithelium bear abundant microvilii extending in between the rods and cones. The rods are longer, slender and cylndirical. Rods out number cones and perceive light in dim light conditions while cones perceive colours in bright light. Cones are shorter, thicker and club shaped. Each retinal cell has a nucleated cell body and a photosensitive outer segment resting upon the pigmented epithelium and an inner segment between these two. Neuronal elements of retina are bound together by supporting glial cells called Mullar cells. Pigments found in photoreceptors include retinal (retinylidene proteins) for example rhodopsin in animals). The retina is an area on the back of the eye. Light falls on the retina and on the rods and cones that are on the retina. These convert light input into visual images in our mind. Rods contain a higher amount of photopigments and are more sensitive to light than cones, which make the rods useful for seeing at night or in dim conditions.

There are ten retinal layers; the two layers that pertain to the rods and cones are the outer nuclear layer, containing the rod and cone inner segments, and the photoreceptor layer, where the outer segments of the rods and cones are located. The inner segment of the rods and cones contain the cell's nucleus, mitochondria, Golgi apparatus, and all of the other elements of the cell that allow it to functions properly. The outer segments of the rods and cones contain a protein known as opsin. Retinal is a specific portion of the opsin protein that is affected by light. When a particle of light comes into contact with the retinal portion of the opsin, the retinal undergoes a chemical change. Rods are designed to be stimulated more easily by smaller amounts of light. However, they lack the ability to detect color differences or to see in fine detail. Rods function better in the dark for detecting movement. The cone cells are much smaller and are responsible for providing fine detail and color vision.

\section{Therapeutics for neonatal diseases}

Stem cell cultures are used to seek new, healthy specialized cells that can be used to replace damaged cells in the eye. Stem cell transplants are potentially used to treat various eye-specific pathologies mainly to replace defective retinal ganglion cells and photoreceptors cornea or lens [39] (Figure 4). There are several categories of stem cells which are used in different ways, to treat neonatal eye disorders. Autologous stem cells are used in personalized regenerative medicine mainly for treatment of ocular surface diseases by using selective tissue grafts for transplantation of the corneal surface layers (Figure 4). Healthy retinal cells can be derived from human embryonic stem cells (hESCs) for treatment of retinitis under defined culture conditions for the same. But neural impairments related to vision loss are most challenging to treat because neurons do not under go regeneration and microglia transplantaions are impossible to done.

Cornea is the transparent front part of the eye whose transparency depends on a unique extracellular matrix secreted by stromal keratocytes and mesenchymal cells of neural crest lineage [40]. The cornea is covered by a stratified epithelium that contains stem cells which form limbus. Corneal transparency in various animal eyes is maintained by enzymatic crystallins. It is the most anterior segment of the eye that provides exquisite vision. It acts as a major protective shield to the eye and represents two thirds of its refractive power. It is made up of three distinct cell layers of different developmental origins: the outer, epithelial layer develops from the ectoderm overlying the lens vesicle; whereas iter, the stroma and the endothelium have mesenchymal origin. Its stromal cell layer is self-renewing epithelium that contains resident stem cell population. The cornea is derived from ectodermal/neural crest cells and formed through a cascade of molecular mechanisms which provides it specific optical features which are necessary for refractory function. Cornea is the transparent exposed portion of the tunic which focuses light in the eye. It is an important visual structure that is needed for a clear vision by refracting light onto the lens, which in turn focusing on the retina. It is a vital tissue that remains poorly protected from the environment and face toxic dust and heat exposure. Corneal limbal defects related to opacity and neovascularization can be restored by using epithelial stem cells reside in limbal stroma and the corneal-endothelium [41]. Moreover, during cornea formation and maturation, large population of epithelial stem cells is sequestered towards the local sites for providing a long lasting source for renewal in the adult [42]. Corneal cells are highly sensitive to heat, light and temperature, these remain constantly damaged and replaced by new cells.

Figure 4. Showing use of stem cell therapy, scaffolds and biomatrixes for regeneration of visual tissues.

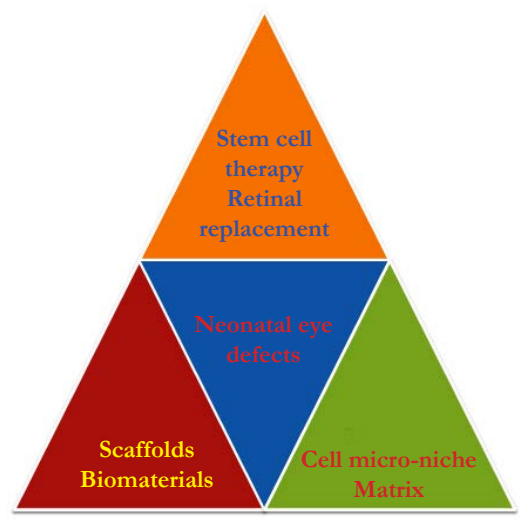


In a normal functional eye damaged cells or aging epithelial cells (epithelium) are continuously replaced by population of stem cells (SC) throughout life. A small population of limbal stem cells found at the edge of the cornea, which easily replace damaged cells, and repair physically injured part. Once these cells lost due to injury or disease, the cornea can no longer be repaired. A permanent injury in cornea may affect the ability of light to enter the eye, and results in a significant loss of vision. Natural corneal defects appeared as a bilateral disorder known as limbal stem cell (LSC) deficiency that can be cured [43] by using autologous LSCs (Limbal stem cells) transplantation [44]. But to procure autologous corneal stem cells is not possible in patients facing bilateral limbal stem cell deficiency (LSCD). However, limbal stem cell tissues obtained from healthy eye can repair the cornea and give the patient to restore their vision. Though it is a cumbersome job to find donors and assure compatibility of stem cells with the cornea. In extreme cases of patient damaging his both eyes, it may not be possible to obtain any limbal stem cells. But stem cells found in the optic nerve of many animals can overcome this problem. CNS stem cells are inhibited and remain dormant after injury. Injecting stem cells into damaged spinal nerve tracts can rejuvenate spinal cord in man.

Failures of corneal epithelial stem cell transplatation can result in painful and blinding disease of the ocular surface [45]. Mainly corneal epithelium or corneal epithelial layer get injured due to severe environmental stress mainly heat, light and high thermal temperature. All these factors results in dysfunction of transplanted cells and leads to reduction of visual clarity and loss of vision. These corneal epithelial injuries can be repaired by using limbal stem cells but it is very slow in diabetic patients. In case of extensive chemical burns or physically injured corneas only cure is limbal stem cell deficiency [46]. However, for corneal epithelial cell renewal and wound healing appropriate integration and coordination of cell signaling events are highly needful. In such cases, treatment may involve transfer of growth factor and normal adult stem cells to the ocular surface [47] (Figure 4). Topical tacrolimus treatment also cause significant decrease in corneal vascularization and reduce cellular inflammation in cells [48]. Similarly, insulin-like growth factor 1 (IGF-1) are also used to form threedimensional ocular-like structures from human embryonic stem cells (hESCs) [49]. The transformation of the oval optic vesicle to a hemispheric bi-layered optic cup involves major morphological changes during early vertebrate eye development [50].

Cornea is a highly organized, transparent connective tissue that is maintained by keratocytes. These cells are quiescent mesenchymal cells of neural crest origin. A small population of cells in the mammalian stroma displays properties of mesenchymal stem cells, including clonal growth, multipotent differentiation, and expression of an array of stem cell-specific markers. In cell culture medium corneal stromal stem cells (CSSCs) undergo extensive expansion without loss of the ability to adopt a keratocyte phenotype [51]. The corneal stroma is large repository for stem cells but peripheral cornea and limbus are also good sites. These peripheral and limbal corneal stromal cells (PLCSCs) are known to produce mesenchymal stem cells in vitro. Both corneal stromal and epithelial progenitor show transdifferentiation ability [52] and can be used for the treatment of many systemic lysosomal storage disorders [53]. For derivation and formation of various cell types from progenitor or stem cell of the keratocyte maintaince of niches is highly required. It also plays an important role in corneal regeneration [54]. Topical administration of eye drops is the major route for drug delivery to the cornea. It is extensively used in alkali-induced corneal wound [55]. Topical OFSC (orbital fat derived stem cells) administration is provided to promote corneal tissue regeneration through ameliorating acute inflammation and corneal epithelial differentiation. For repairing of neonatal eye defects and regeneration of visual tissues scaffolds, biomatrixes and stem cell therapy are important tools [55] (Figure 4).

Emulatiion of corneal stromal tissue is most challenging task in bioengineering to have artificial human cornea. It is very difficult to reproduce highly ordered microstructure, with all biomechanical properties and optical transparency of this tissue [56]. Therefore, both human corneal stromal stem cells (hCSSCs) and RGD surface-coupled patterned silk film are used to develop highly ordered collagen fibril-based constructs for corneal regeneration and corneal stromal tissue repair [56]. From human embryonic stem cells (hESCs), corneal endothelial cells (CECs) can be derived similar to native human CECs [57]. These cells have potential application in replacement therapies as substitution for donor CECs [59]. Cultured human CECs show stem cell markers including nestin, OCT3/4, and GFAP which differ according to the culture media and associated proliferation rate [58]. Mouse adipose tissue mesothelial cells (ATMCs) show similar morphologic and biochemical characteristics with mouse (CECs). These show capacity to adhere to the decellularized basal membrane of human anterior lens capsules (HALCs) and are used as potential tissue-engineered source for corneal endothelium replacement [59] (Figure 5).

Corneal transplantation is best therapetics for severe corneal disorders. It is the primary treatment option to restore vision for patients with corneal endothelial blindness. For transplantation purpose tissue-engineered corneal endothelial grafts are constructed by using cultivated human corneal endothelial cells. These can be isolated from cadaveric corneas and may serve as a potential graft source [60]. Similarly, transplantation of human umbilical mesenchymal stem cells is found successful to repair corneal defects in mice [61]. TECE (Tissue-engineered corneal endothelium) transplantation aids in corneal transparency and thickness, while stem cell therapy can restore corneal endothelial dysfunctions [62] (Figure 5). Patients with advanced corneal disease show very poor conventional corneal transplantation success and need keratoprosthesis (KPro) for visual rehabilitation. For construction of KPro is poly(methyl methacrylate) (PMMA) is used in central optical core and a donor cornea as skirt material [63] .

Human corneal endothelial cells (HCECs) shows limited proliferative ability in vitro. However, for the cultivating HCECs, conditioned medium (CM) is obtained from human bone marrow-derived mesenchymal stem cells (MSCs) (MSC-CM) for consistent expansion of HCECs. Interactions between stromal and epithelial cells play important roles in the development, homeostasis, and pathological conditions of the cornea. These interactions need number of soluble as critical factors and growth factors which are secreted from corneal stromal cells and contribute to the regulation of proliferation and differentiation of corneal epithelial cells (CECs) [64]. Basal layer of corneal epithelium can repair epithelial cell damage but these could not regenerate in vivo. More-excep- 
Figure 5. Stem cell derived nerve cells are used for the replacement of defective retinal cells.

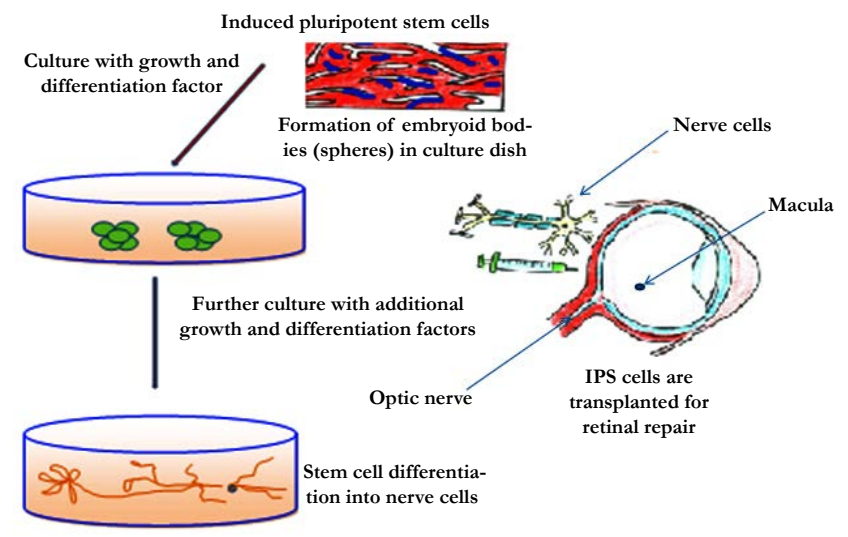

tionally stem cells found in basal layer convert into endothelial cells under certain circumstances. Both stromal cells and epithelial cells may act in concert in the cornea [64]. Stromal stem cells show biocompatibility in grafts and make sheets of decellularized human corneal stroma with or without the recellularization [65]. Another emerging therapeutic strategy consists of obtaining and implementing human progenitor cells of different origins using tissue engineering methods (Figure 4).

Human neural crest cells (hNCCs) derived from human pluripotent stem cells (hPSCs) are embryonic migratory cell population. These cells showed the ability to differentiate into a wide variety of cell types [66] and also exhibit neurogenic potential [67]. Similarly, adipose-derived mesenchymal stem cells (ADMSCs) differentiate into corneal epithelium-like cells after transfection with Pax6 gene [39]. These cells are good source of generating corneal epithelium- for construction of tissue engineered cornea. Corneal stroma contains stem cell population which are heterogeneous in nature and show similarity with neural crest progenitor cells. These cells are also used for surgical treatment of fungal keratitis [68]. More specifically, visual cells and retina are formed by an ancestral neural circuit that works under a conserved network of genes (including Pax6/eyeless) [69]. These genes create differences in morphology and structure of photoreceptor-type usage and lens. Human adipose-derived cells (hASCs) found overlaid on scleral contact lens (SCL) act as carrier and prolieferate to finish ocular alkaline burn [70] (Figure 5).

\section{Restoration of vision}

Keratocytes derived from human embryonic stem (hES) cells are used in cell-based therapy mainly for removal of corneal blindness. Mainly human fetal keratocytes (HFKs) start differentiation into neural crest-derived tissues when challenged in an embryonic environment [71]. These cells are maintained and expanded in feeder-free culture medium. These cells differentiate into neural crest cells by using the stromal-derived inducing activity of the PA6 mouse embryonic fibroblast cell line [72] (Figuer 5). Keratocytes are potentially used for restoration of vision and have enlarged biomedical engineering applications. But these specialized cells can not readily expand in vitro. Though culturing corneal keratocytes is very difficult because keratocytes growing in a monolayer rapidly lose their stellate morphology and cease to express keratocyte markers such as keratocan, lumican and aldehyde dehydrogenase 1 family, member A1 (ALDH1A1) [41]. Similarly, stem cells found in corneal limbal region need specific microniche [41].

Dental pulp contains a population of adult stem cells much similar to corneal stroma. These cells develop embryonically from the cranial neural crest. Morever, adult dental pulp cells (DPCs) isolated from third molars showed the capability to differentiate into keratocytes, cells of the corneal stoma. After inducing differentiation in vitro, DPCs express molecules characteristic of keratocytes, keratocan, and keratan sulfate proteoglycans at both the gene and the protein levels. DPCs that are cultured on aligned nanofiber substrates are used to make corneal stromal-like constructs mainly tightly packed, aligned, parallel fibrillar collagen of native stromal tissue. Keratocytes derived from DPCs can be used for clinical application mainly in cellular or tissue engineering therapies for corneal stromal blindness [73]. During stromal healing, keratocytes get transformed to motile and contractile myofibroblasts largely due to activation of transforming growth factor- $\beta$ (TGF- $\beta$ ) system. Keratoconjunctivitis sicca or dry eye disease is an immunemediated multifactorial disease largely found in humans and dogs [74]. Figure 5 illustrates stem cells derived nerve cells for retinal replacement.

\section{Corneal wound healing}

Corneal wound healing is a complex process involving cell death, migration, proliferation and, differentiation. It also needs extracellular matrix remodeling. Many similarities are observed in the healing processes of corneal epithelial, stromal and endothelial cells, as well as cell-specific differences. Corneal epithelial healing largely depends on limbal stem cells and remodeling of the basement membrane. Improved methods are developed for growing limbal stem cells in the laboratories which are becoming highly feasible biomaterials for better transplantation. However, to overcome the scarcity of stem cells new potential sources of stem cell derivation have been searched. In the laboratory limbal stem cells can be derived from embryonic stem cells or induced pluripotent stem (iPS) cells. These are used as endless source for generating large quantities of limbal stem cells for therapeutics of patients mainly those who want to avoid surgical operation and are in great need (Figure 5).

The mammalian cornea contains a population of basal epithelial stem cells which maintain homeostasis and continue repairing. Corneal stem cells are used to generate corneal cells for long term supply of source material [75]. These cells transform to precursor 
cells (epithelial cells) in spheroid cell culture [76] and develop in to keratocytes [80]. These cells also participate in corneal regeneration [77]. Besides, conventional allograft therapy, corneal scarring method is also developed to avoid allograft rejection and to reduce complications related to endothelial failure. In explants culture, stromal cells are used as autofeeder layer and expansion of human corneal epithelial cells [78]. However, for deriving limbal epithelial stem cells for healing purpose, a micro niche is needed for self-renewal of the corneal epithelial stem cells through out life. In addition, few growth factors, stromal niche cells, and specific extracellular matrix compositions are also required to maintain this environment [79]. Moreover, cultured corneal epithelial cells are considered to be promising material for constructing bioartificial cornea [80]. Similarly, mesenchymal stem cells (MSCs) acquire certain characteristics of corneal epithelial cells [81]. These cells are isolated from noncorneal tissues for stem cell therapies of cornea. These cells show immuno-modulatory properties, and claims to transdifferentiation into corneal cells [82] (Figure 5).

Corneal endothelial dysfunction is a major problem in corneal transplantation. Similarly, endothelial cells healing needs migration and spreading of cells after proliferation [83]. However, HCECs (human corneal epitheial cells) cultured on the PCM-DM provides a feasible xeno-free matrix substrate is used in tissueengineered based therapy of corneal endothelial dysfunction [84]. Therefore for therapeutic long ex vivo culture is needed to generate enough cell numbers for transplantation [85]. Limbal biopsy-derived stromal cells (LBSCs) expanded rapidly in media containing human serum that are highly clonogenic. These could generate spheres expressing stem cell genes (ABCG2, Nestin, NGFR, Oct4, PAX6, and Sox2) [86]. These LBSCs (limbal biopsy-derived stromal cells) are capable of corneal stromal regeneration and can be used as potential source for autologous stem cells for treatment of corneal stromal blindness [86]. Allogeneic limbal mesenchymal stem cell (LMSC) therapy is used for corneal healing after a severe chemical burn, but route of administration of LMSCs differs in its therapeutic effect [87]. However, direct treatment of corneal scarring can be done by using autologous stem cells that can reduce the need for corneal grafts (Figure 5).

Healthy corneal endothelium maintains corneal clarity. Once corneal endothelium get damaged and loss of cell count ocuurs it results in severe visual impairment. For this purpose barrier and pump functions are essentially normalized for the maintenance of corneal transparency and restoration of corneal endothelial dysfunction [88]. However, to maintain a smooth optical surface, corneal epithelium should be continuously renewed to function as a barrier so that it could protect the eye from various environmental insults. Further, adult corneal epithelium is normally maintained homeostatically by an integrated process of cell proliferation, migration, differentiation, stratification, and desquamation/apoptosis. Failure of endothmation results in persistent corneal defect that leads to the blindness. Some times ocular surface defects also cause vision impairment or even total blindness. However, to restore the ocular surface in patients, autologous extraocular stem cells are used to avoid host immunosuppression of allogenic transplants. Human adult mesenchymal stromal cells, represents a significant breakthrough in the treatment of certain eye diseases. These are less invasive and more feasible for ocular surface regeneration [89] (Figure 5).

\section{Regeneration of eye components}

Corneal epithelium contains a population of progenitor cells which contineously repair cornea and restore its normal function byself renewal. However, cellular integrity of corneal epithelium maintains cornea's transparency and vision. Currently, cell-based therapies are used in replacement of defective eye components mainly for restoration of visual receptors. These are also used for treating limbal stem cell deficiencies. For this purpose both cultured limbal epithelial transplantation and cultured oral mucosal epithelial transplantations are done. Besides this, sphere-forming cells are generated from peripheral corneal stem cells. These are used as potential source of progenitor cells for treatment of corneal degenerative diseases [90]. Normally, stratified multilayered collagen fibril lamellae with orthogonal orientation determine the robust biomechanical properties of corneal tissue but to creat uniform collagen fibril size and interfibrillar spacing are very critical to maintain optical transparency [91]. Moreover, recapitulating the microstructure of the native human corneal stromal tissue is key success in engineering the corneal tissue. But recapitulation of human corneal stromal tissue is a most challenging step in engineering human corneal tissue because of the difficulty in reproducing its highly-ordered hierarchical ultrastructure to generate required optical transparency [92] (Figure 5).

Among different possible reasons of congenital human cataracts point mutations in the alphaA-crystallin gene are main architects [93]. AlphaA-crystallin (Cryaa/HSPB4) is a small heat shock protein and molecular chaperone that prevents nonspecific aggregation of denaturing proteins. Instead DrGRIFIN protein belongs to galectin family member function as a crystalline material and show carbohydrate-binding properties [94]. Similarly, Eph receptor tyrosine kinases and their ligands such as ephrins, regulate the development and maintenance of normal corneal architecture [95]. Therefore, an early diagnosis and appropriate therapy be needed because p63 gene mutations have a critical role in maintaining the integrity of the ocular surface in the setting of limbal stem cell deficiency. There are other reasons of ocular surface problems such as lid disease, meibomian gland dysfunction and toxicity from topical medications. Therefore, patients should keep under regular monitoring at frequent intervals to avoid adverse secondary effects of all different medications provided [17] (Figure 5).

\section{Restoration of retinal pigment epithelial cells}

Retina is pigmented component of the eye which detects light, once damages; it leads to the onset of blindness. Number of methods are available which are potentially used to restore physiological functions of pigmented retinal epithelial cells. These cells perform a number of important functions to adjacent retina but with the age macular degeneration (AMD), retinitis pigmentosa and Leber's congenital aneurosis abnormalities occurred. Upon injury retinal epithelial cells stop working properly and also affect retinal function. However, for treatment of such retinal disorders/diseases can be done by replacing the damaged RPE cells with transplanted healthy cells. For transplantation purpose RPE cells can be derived from both embryonic stem cells and induced pluripotent cells in the laboratory. Such experiments never become successful in case of complete damage, and RPE cell replacment found effective only in least working retina, or level 
of vision restored at early stages of the disease. Unlike RPE cell transplantation, direct repair of the retina is also possible those who have already lost their vision. However, cell transplantation gives hope to the patients with macular degeneration, and facing loss of light-sensitive photoreceptor cells in the retina. Other defects are malfunctioning of retinal circuits which stop working properly or die off. Such types of restorations of retinal cells become possible only after activating the optic nerve.

By using stem cell technology different types of retinal cells can be derived for replacement therapy to treat retinal diseases like retinitis pigmentosa and glaucoma. Similar retinal stem cells have bee obtained from ciliary epithelium found at the retinal margin of the adult mouse and human eyes. These cells divide in vitro in the absence of growth factors to generate clonal, self-renewing spheres which can generate all the retinal cell types. But various factors which impose anti-proliferative effects on RSCs (Rare retinal stem cells) are secreted by the adult lens and cornea which obstruct the proliferation of RSCs in vitro. Few important principal factors which show anti-proliferative effects are bone morphogenetic protein (BMP)2, BMP4, and secreted frizzled related protein [96]. The retinal pigment epithelium (RPE) is a monolayer of cells that found underlying neural retina [97]. It proliferates to form a plastic tissue, capable of generating lens and retina, but during early development its remains normally non-proliferative throughout life [98]. Similarly in vitro regeneration of optic nerve damage is possible by using certain growth factors. In animals it may assist in regaining the ability to detect overall movement of the visual field and were able to perceive light.

\section{Lens regeneration}

Lens is situated in the interior of the eye, just behind the iris. It is clear, crystalline and glassy in appearance and biconvex in form. Lens is formed from a single progenitor cell lineage after multiple states of differentiation. Lens opacity is disturbed due to protein aggregation that generates cataract. Lens regeneration occurs in newts for repairing of lost tissue [99]. Defective tissue is replaced by transdifferentiation of cornea epithelial cells [100] in presence of epithelium-derived growth factor (LEDGF/ $\mathrm{p} 75)$. It is is a transcription co-activator that shows epithelial cell gene regulation and evoke stress responses. The Drosophila eyeless gene plays a central role in fly eye development. This gene controls a subordinate regulatory network consisting of eya and dac genes [101]. Similarly, LEDGF/p75factor plays an important role in lens epithelial to fibre cell terminal differentiation [102]. Id or msh gene expression regulators are required for limbo-corneal and conjunctival [103]. Three different FGF receptor (Figure 1, Figure 2, Figure 3) participate in developing less. These genes induce differentiation of lens epithelial cells into fiber cells both in vitro and in vivo. Fggire1 plays an independent, essential role in lens development [104] (Table 2).

An initial event that triggers eye morphogenesis is physical contact of optic vesicle with head surface ectoderm. This important interaction leads to lens specification followed by coordinated invagination of the lens placode and optic vesicle, resulting in formation of the lens, retina and retinal pigmented epithelium [92]. Cell specific culture systems have been developed to generate eyelike structures mainly related with lens, neural retina, and retinal pigmented epithelium (RPE) cells from undifferentiated embry- onic stem cells. These RPE-like cells transform into in eye-like structures when transplanted these form neuronal retina [105]. Many ocular diseases, such as retinitis pigmentosa and age-related macular degeneration, caused due to damage of specific cells which can not be normally repaired or replaced. For treatment of these degenerative diseases transplantation of healthy fetal cells from a suitable donor remains workable [106].

Lens and retina of eye are also formed from transdifferentiation of stem cells [107]. Similarly, lens regeneration occurs by processes of both cellular dedifferentiation and transdifferentiation that also generate other cell types [108]. In vertebrates eye tissue regeneration also occurs after transdifferentiation of one cell type to another. Transdifferentiation belongs to a wider class of cell type transformations called metaplasias which also includes cases in which stem cells of one tissue type switch to a completely different stem cell. Similar transdifferentiation also occurs in functional organs such as tentacles, feeding organ (manubrium) and striated muscles of jellyfish (Anthomedusae) in vitro [109]. Transdifferentiation starts after induction of molecular and cellular mechanisms that underlie the switches in phenotype, together with their significance to organogenesis and regenerative medicine. Lens regeneration in newts proceeds from the dorsal margin of the iris where pigment epithelial cells (PEC) re-enter the cell cycle and transdifferentiate into lens [110]. This is the the main reason that adult newts are able to regenerate their retina and lens after injury or can do complete removal through transdifferentiation of the pigmented epithelial tissues of the eye [111].

Epitheial cells found in anterior portion of the lens capsule show pluripotency, proliferation and migration potential. These are used for opacification after cataract surgery [52]. Besides transdifferentiation, reprogramming of pigmented epithelial cells (PECs) is also important process that involves in newt lens regeneration [112]. After lens removal, PECs in dorsal iris dedifferentiate and revert to stem cell-like cells, and transdifferentiate into lens cells. During this phase global histone modifications are needed for reprogramming of PECs [112]. Human embryonic stem cells differentiate into large quantities of lens progenitor-like cells in new 3-stage system and differentiated 3-dimensional lentoid bodies [113]. Inhibition of BMP signaling by noggin triggers differentiation of hESCs toward neuroectoderm [113].

Two genes OCT4-pg1 retrogene and NANOG play important role in self-renewal and differentiation of pluripotent cells in a developing eye [114] (Table 2). Normally, for stem cell maintenance, cellular proliferation and differentiation Wnt-signaling pathway acts as an important regulator. It is also followed during cancer development in various tissues. Its normal function states retinal development while failure may states occurrence of a disease [115]. A third gene Pitx3 maintains lens epithelial phenotype and prevents inappropriate fibre cell differentiation during lens development [116]. BetaB2-crystallin is not essentially required for the normal development of a transparent lens in the mouse but it plays important role in maintaining the transparency of the lens after birth. It interacts with other crystallins to increase their resistance to thermal denaturation and oxidative stress [117]. Lens crystallins are expressed in mammalian corneas and cultured corneal cells [118] (Table 2). Germinative zone of lens contains stem cells [119] which can form lens epithelium [120]. 
Neurogenesis in outer neuroblast zone and the secondary lens fibre formation takes place during 6th week of development [121]. It also passes through cell proliferation and transdifferentiation of lens epithelial cells (LECs). But its conversion to myofibroblasts results in secondary cataract formation. Neurogenesis show increased expression of alpha-smooth muscle actin (alpha-SMA) that is influenced by other factors such as $\beta$-FGF, TGF-beta2, EGF and IGF-1 [122] (Table 2). In the adult organism, tissue renewal and regeneration depends ultimately on proliferation of somatic stem cells. Similar proliferation and differentiation is also required in eye tissues. Lens epithelial cells show slow cycling and possess ability to differentiate terminally into fiber cells. These can be obtained from stem cell lineage [123]. In this process telomerase plays a protective in lens epithelial cells [124].

In defective photoreceptor cells like retina and lens re-activation of many of the genes is highly important. A similar environment be needed that is required during development of the eye for cellular differentiation and gene invoking. In anuran amphibians regeneration of the retina occurs through differentiation of stem cells in the ciliary marginal zone and transdifferentiation of the retinal pigmented epithelium [125]. Lens regeneration in adult newts occurs via transdifferentiation of the pigment epithelial cells (PECs) of the dorsal iris. Both up-regulation and down-regulation of few genes also leads to dedifferentiation [126]. Moreover, during lens and limb regeneration in newts mammalian stem cell pluripotency-inducing factors are expressed. Further, during differentiation process stemness should maintain because a slight change in factors and environment may stop corneal epithelial, stromal and endothelial cell differentiation $[127,128]$.

Cataract in man is a complex disease that is caused due to effect of genetic and environmental factors [113]. It happens due to exposure of photoreceptors to strong light, physical stress, heat and sweating in high humidity and temperature. All these factors create defects in lens. Similarly congenital cataract also occurs in neonates during development period due to stress response and heat shock factors (HSFs). Environmental factors, drugs and physical stress play crucial roles in differentiation and development of lens. Heat shock transcription factor 4 (HSF4) deficiencies leads to defect in lens epithelial cell (LEC) due to obstruction of differentiation [129]. Hence, proper differentiation of both the corneal endothelium and the iris is required for development of tissues in the anterior chamber [130]. Similar cell proliferation is needed for formation of optic cup, stalk, the cornea, and the lens.

Stromal keratocytes found in the stroma of the limbus can be expanded in culture for obtaining limbal fibroblasts (LFs). These cells showed similar characteristics to bone marrow mesenchymal stem cells (BM-MSCs) and are used to maintain the epithelial stem cell phenotype in the limbal region. Limbal fibroblasts showed a greater potential for differentiation into corneal epithelium. Similarly, tissue-specific adult progenitors which show reprogramming capacity can be used for obtaining desirable cells types for therapeutic purposes [128]. But it will need more favorable environment for stage specific differentiation [128], otherwise there occurs a loss of cell lineage that may form lens placode and any other tissue [131]. However, new simple, reproducible, animal-material free methods are used for cultivating and characterizing cornea limbal epithelial stem cells (LESCs) on human lens capsule (LC) [132]. Both corneal epithelium and lens share a common pool of precursors [133]. Increasing concentration of calcium and epidermal growth factors (EGF) aids in stem cell proliferation, regeneration and repair (Table 2).

Pax6 is the universal gene that regulates eye morphogenesis. It is also expressed in the ocular surface epithelium from early gestation until the postnatal stage [134]. Similarly, Lim2 gene plays a critical role in establishing the correct internal refractive properties of the crystalline lens [135] (Table 2). Stathmin a small cytoplasmic phosphoprotein is required for regeneration of injured neural tissues in Japanese common newts (Cynops pyrrhogaster). It is a microtubule regulator [136]. Similarly, BMP signals (bone morphogenetic protein signals) are also required to induce olfactory and lens placodal cells from progenitor cells found at the anterior neural plate border [137]. Ciliary body is a good source of lens stem cells which are used for generation of corneal epithelium [138]. Human anterior lens capsule are used as a biologic substrate for the ex vivo expansion of limbal stem cells in ocular surface reconstruction [106]. There are many ocular surface disorders that are caused due to damage in the limbal region that results in destruction of corneal stem cells. For lens regeneration, induction of transdifferentiation in pigment epithelial cells is highly needful in stem cells bioengineering [139]. Moreover, for treatment of several ocular surface diseases limbal transplantation or cultivated limbal cell transplantation are usually done [140]. Other methods that are followed for control of ocular disease and prenatal genetic eye related genetic disorders preclude ocular stem cell populations based lentiviral vector-based gene transfer [141]. More specifically, multipotent cells found within the iris pigment epithelium (IPE) [142] can be used for regeneration of lens tissue in newts because of their developmental plasticity. Similarly, neural retinal regeneration occurs in the anuran amphibian Xenopus laevis during post-metamorphosis follows transdifferentiation of retinal pigmented epithelium [143]. Moreoften, for cell replacement therapy reprogramming of cells from one tissue type to another needs manipulation of expression of transcription factors. These reprogrammed cells [144] induced by certain transcription factors maintain apoptosis and may involve in the perforation of the cornea in patients [145]. These cells can be used for therapies for many human diseases.

\section{Maintaining stem cell microenvironment}

Maintainace of microenvironment in cell culture is highly important for regulation of interactions of various factors and stem cell function. It is also essential for maintaining cellular differentiation, corneal transparency, vision and ocular surface reconstruction [129]. It is also required for restoration of important signaling pathways for differentiation of epidermal/epithelial cells to derive specific epithelial cell types [146]. Similarly, limbal niche is required for differentiation of limbal stroma [157] after an injury [148]. Further, for derivatization of tissue-specific stem cells and secretion of regenerative factors and matrix components stem cell microenvironment should be maintained for achieving larger therapeutic successes [43]. In maintenance of microenvironment extracellular matrix plays a central role in regulating stem cell behavior, corneal differentiation, and participation in corneal wound healing. These are micro-mini factors participate in various cellular processes and decide cell division patterns in corneal stem cell populations. These factors also decide stem cell division as asymmetrically or symmetrically. There are certain factors which 
maintain environmental signals such as cytokines and growth factors and regulate corneal epithelial stem cells when used for corneal wound healing [149].

Mesenchymal stromal/stem cells (MSCs) are promising stem cell type which is used for corneal wound healing and therapeutics [43]. Though stem cells exist in different parts of the eye, such as the retina, lens, conjunctiva, corneal stroma, Descemet's membrane but these require ceratin induction factors that could induce transdifferentiation of stem cells into corneal epithelium-like cells by in vitro co-culture with immortal corneal epithelium cells. These are used as a potential source for ocular surface regeneration [150]. However for development of corneal endothelium proliferating cells should express progenitor markers [151]. Human limbal epithelial cells (hLECs) are obtained from organ culture of corneal-scleral (OCCS) rims for therapeutic purposes [148]. In addition, spheroids of rabbit and mouse corneal stromal cells (CSCs) are also generated in vitro for reprogramming, bioprinting and tissue engineering [152]. These positively express the mesenchymal and stem cell phenotypes.

It is clear that niche factors are highly important in the maintenance and regulation of stem cells. Morespecifically, limbal stromal cells are also used to maintain niche in in vitro co-cultures [153]. Human limbal epithelial cells (HLE) and corneal stromal stem cells (CSSC) reside in close proximity in vivo in the corneal limbal stem cell niche. Thus, limbal stromal cells with an intact cell-cell contact help to maintain LSCs in an undifferentiated state in vitro during expansion. These need specific tissue environment (niches) similar to stem/progenitor cells reside in eye. RAFT TEs are also used for restoration of limbal niche following ocular surface injury or disease [154]. For therapeutic purposes mesenchymal-like stem cells are derived from limbal area of the corneal stroma [155]. Limbal epithelial stem cells (LESCs) also need specific niche to maintain the transparent ocular surface required for vision. This micro-niche is also provided by limbal crypts niche for the resident LESCs and associating and dendritic pigmented limbal melanocytes and elongated limbal stromal cells [156].

LSCs (limbal stem cells) were found effective in the treatment of highly difficult human wounds, such as diabetic ulcers, recalcitrant chronic wounds, and even persistent epithelial defects of the cornea. But these cells need limbal-like environment in the transplanted area of cornea [157]. Normally, in cell culture, stem cell niche is maintained by physically protected microenvironment in close proximity to a variety of neighbouring niche cells. It leads to form epithelial cellular sheets which can be used for treatment of limbal stem cell deficiency [158] mainly for repairing, wound healing and regeneration of corneal tissues [159]. Similar, niche environment is also maintained by amniotic membrane during culture of LSCs in medium. Thus, designing and recreation of elements of various stem cell niches mainly 3-dimensional niche architectures can be used for having more biocompatible substrates, matrixes, sheets and factors. These can be used for creation of defined topographical features in stem cell derived tissues and make them more applicable for numerous tissue-engineering applications [160].

\section{Limbal stem cell deficiency}

Limbal stem cell deficiency (LSCD) occurs due to depletion of limbal stem cells that results in corneal blindness [163] and im- parts poor vision due to corneal neovascularization, epithelial defects and impaired corneal wound healing [164]. Both are permanent epithelial defects which persist for longer period as impair vision [165]. It can be cured by delivering progenitor cells on a contact lens and make them viable and effective after transplantation [166]. Limbal stem cell deficiency is occured due to direct destruction of limbal stem cells or indirectly from altered limbal stromal niche. It is also caused due to severe ocular injuries occurred after exposure of physical environment and chemical agents like sulfur mustard (SM) which cause acute corneal erosions and inflammation of the anterior segment. It also leads to invasion of conjunctival epithelium over the cornea and imposes varying degrees of corneal changes such as neovascularization, inflammation and recurrent erosions. Persistent epithelial defects and destruction of basement membrane of epithelium stops stromal healing in pateints [167]. Similarly, lesions on the ocular surface destroy the stem cells from the limbus and cause limbal stem cell deficiency. LECs (HLA-typed allogeneic) expanded in ex vivo can be harvested from the same living-related donors and are used to reconstruct ocular surface in cGVHD [168]].

Mesenchymal stem cell transplantation [42] or corneal transplantation with cultivated limbal or oral epithelium is best option for removal of limbal stem cell deficiency (LSCD). It has wider application in ocular surface reconstruction [169]. But it needs replenishment of depleted limbal stem cell (LSC) pool by either limbal tissue transplantation or use of cultivated limbal epithelial cells (LECs). Similarly, keratolimbal allograft surgery and deep anterior lamellar keratoplasty are also used for removal of limbal stem cell deficiency (LSCD) [170]. Human limbal mesenchymal cells (HLMCs) express cytokeratin 3, Np63 and connexin 43 (Cx43) and are used as feeder layer for the human limbal epithelial cells (HLECs) [171]. HLMCs are used as a bioengineering product which is biologically safer and used for the clinical applications [172]. LSCD is also related to defects in lens [123] and arises due to infectious keratitis [173]. For treatment of LSCD pateints cultivated corneal limbal epithelial transplantation (CLET) and autologous tissue transplantation is also used for ocular surface reconstruction [174]. Hence, for regeneration elimination of xenogeneic components is highly important [175]. Boston Kpro is also used for restoration of short-term visual and anatomical corrections in patients with bilateral LSCD [90]. HSPC (Hematopoietic stem/progenitor cell) transplantation is done for to treatment of corneal defects in cystinosis pateints [21].

\section{Stem cell therapy}

Stem cells are self renewal cells which enormously devide to form to any cell type. These are used as a source of new, healthy specialized cells to replace damaged cells in the eye. There are several stem cell types which could be used in different ways, depending upon the particular disorder to be treated. Stem cells are used in conventional corneal transplantation, to restore cellular layer of the cornea [176]. Stem cell (SC) therapy is used for treating various eye defects/pathologies mainly ectopic injuries. It is also found successful in treating inherited diseases/disorders, and even in case of acquired cellular deficiencies and neuronal disorders. For repairing visual defects neural progenitor cells are delivered to the vitreous layer that can integrate into the ganglion cell layer of the retina. These cells turn on neurofilament genes, and migrate into the host optic nerve. Stem cell therapy is used for treatment of various eye-specific pathologies mainly in retinal degenerative 
diseases. Stem cells also show potential for the production of new biological components that can be used to repair the eye mainly for suitable regenerative medicine for cornea. Stem cells are used for replacing the lost retinal ganglion cells and restoration of photoreceptors.

Biological matrix is used for stem cell growth and transfer that could be possible by using co-culture system [161]. By using human corneal stromal stem cells (dhCSSCs) dorsal root ganglion neurons (DRG) can be differentiated that can restore normal cornea functions [177]. Besides this, engineered transplantable stem cells are also transferred for therapeutic purposes to restore patient-specific cornea or lens functions [39]. Normally mammalian cornea contains a population of basal epithelial stem cells which maintain cornea homeostasis and repair [100]. Induced pluripotent stem (iPS) cells are also used to replace defective optical tissues and cells. These cells can be derived from autonomous fibroblasts by using multiple ectopic transcription factors in culture medium. Recently, ciliary body epithelial cells (CECs) are identified as a new cell type for iPSC (induced pluripotent stem cell) generation that has higher reprogramming efficiency in comparison to fibroblasts [178]. Besides, interstitial cell-telocyte which possesses outgrowth prolongations named as telopodes form heterocellular networks are also used for therapeutic purposes [179]. Optic stem cell therapy seems a good best hope for regeneration of permanently damaged cells. However, its treatment needs continious drug treatments or other exogenous biomaterial implants depending upon the relevant ophthalmological condition (Figure 4).

\section{Human embryonic stem cells (hESCs)}

Human embryonic stem cells (hESC) are used as important resource to obtain any differentiated cell type of the human body [72]. These cells are used for development of lens and its regeneration [131]. Human embryonic stem cells differentiate to form human trabecular meshwork of stem cells are used in therapeutics of glaucoma [180]. Umbilical cord blood mesenchymal stem cells are also used for transplantation purpose to replace injured corneal endothelium. These cells behave like human corneal endothelial cells (HCEC) and show ability to heal ex vivo corneal wounds [181]. These cells are used to replace damaged or diseased corneal endothelium [181]. For cell transplantation specific microenvironmental conditions are required for repairing and wound healing. Human mesenchymal stem cells also differentiate into soft tissues mainly photoreceptor cells [182] while embryonic stem (ES) cells could derive neural retinal lineage cells which can be used to form retinal pigment epithelial (RPE) cells and lens cells [183]. No doubt embryonic stem cells become an important resource of any differentiated cell type of the human body and can provide a limitless supply.

\section{Pluripotent stem cells}

Pluripotent stem cells are self renewable cells which can give rise keratocytes that can be used for treatment of corneal stromal opacities. Its differentiation takes place in vitro that can be induced by co-culture of mouse PA6 fibroblasts in the same medium [170]. Similarly, induced pluripotent stem (iPS) cells are established from somatic cells for generation of corneal epithelial cells [184]. These could be derived from human adult dermal fibroblast
(HDF)-derived co-culture. Similarly, human adult corneal limbal epithelial cells (HLEC) could be derived from iPS cells (L1B41) in presence of Yamanaka 4 factors [184]. This strategy is highly successful for generation of corneal epithelial cells from human iPS cells. This is purely epigenomic in origin in which certain exogenous factors may induce differentiation of epithelial cells into corneal epithelial cells [184].

\section{Mesenchymal stem cells/multipotent marrow stromal cells (MSC)}

Mesenchymal stem cells are multipotent cells which are found in various tissues. These are non-hemopoietic cells, self-renewable which can be isolated and expanded in vitro conditions and transdifferentiate into other type of cells. These cells reside in bone marrow (BM) and support homing of hematopoietic stem cells (HSCs) and their self-renewal. These cells are used for repairing of tissues/cells (essentially those originating from mesoderm). These cells indirectly assist in modulating inflammatory and immune responses and used for treatment of various pathological conditions especially for corneal reconstruction [185]. Mesenchymal stem cells obtained from diverse tissues show immunosuppressive and pro-anti-inflalammatory characteristics [186]. Mesenchymal stromal cells (MSC) are quite similar to bone marrow-derived mesenchymal stromal cells (BM-MSC). These can be grown from the limbus of the human cornea [187]. These cells can be used as supportive cells to facilitate hematopoietic stem cell engraftment and to minimize the deleterious consequences of graft versus host disease by their immunosuppressive function. These cells show robust osteogenic differentiation capacity and are used in healing/repairing of cutaneous defects due to burns or ischemic strokes.

Besides bone marrow mesenchymal stem cells are isolated from various tissues. These are administered to repair injured cornea mainly for its reconstruction, but not to the normal cornea. Similarly, systemically injected syngeneic mesenchymal stem cells (MSCs) are used in transplanted cornea, suppress induction of alloimmunity, and promote allograft survival [188]. This administration of MSCs showed significant and rapid corneal epithelial regeneration under specific stem cell (SC) niche [189]. However, expression of stage-specific embryonic stem cell (ESC)-like properties of these cells can be used for new cell based therapeutics [55]. Mesenchymal stem cells reside in the murine corneal stroma differentiate into chondrocytes and neurocytes which are used in keratopathies [190]. Presence of multipotent human limbal stromal cells resembling mesenchymal stromal cells (MSC) show very high therapeutic potential [191] and facilitate the regeneration of injured tissue [192]. These beneficial effects of hMSCs on tissueendogenous stem cells involving hCEP (human corneal epithelial progenitor cells), provide a basis for using MSCs or MSC-derived factors to treat diseases of the cornea and other tissues [192].

Mesenchymal stem cells (MSC) cells are good source for bioengineering of corneal tissue and for cell-based therapeutics. MSCs participate in tissue repairing by modulating excessive immune responses in various diseases MSCs are used for corneal healing and regeneration. These show wider therapeutic applications in murine models [193]. MSCs protect the ocular surface by suppressing inflammation in DES (Dry eye syndrome) and are used in therapy for a number of ocular surface diseases where inflammation plays 
a key role [193]. Chronic inflammation and neovascularization on the ocular surface may accelerate the disappearance of the amniotic membrane [194]. Mesenchymal stromal cells (MSCs) cultivated from the corneal limbus (L-MSCs) are potential source of cells required for corneal repair. Cultivated limbal epithelial transplantation is done to restore ocular surface burn [195]. Human limbal mesenchymal cells (LMCs) are used to support the expansion of human corneal epithelial stem/progenitor cells (LSCs) in culture [196].

Mesenchymal stem cells (MSCs) differentiate into tissues of mesenchymal origin, and derive different cell types such as fibroblasts, adipocytes, cardiomyocytes, and stromal cells. These cells express surface molecules like CD13, CD29, CD44, CD73, CD90, CD166, CXCL12 and toll-like receptors (TLRs) [197]. These cells display properties similar to mesenchymal stem cells and demonstrate the ability to reproduce an organized matrix in vitro. CSSCs have shown great potential for the development of cell-based therapies for corneal blindness and stromal tissue bioengineering [198]. Therefore, correct specification of cell lineages is essentially needed within the developing cornea for normal vision [45]. Umbilical mesenchymal stem cell transplantation is a promising treatment that involves keratocyte renewal or replacement. But there is a need to develop alternative treatment regimens for congenital corneal diseases of genetic mutation particularly related to corneal blindness [199]. For this purpose, keratoplasty is the most effective treatment but there is a lack of donated cornea that prevents corneal transplantations. Umbilical mesenchymal stem cells can be easily isolated, expanded and stored in liquid nitrogen, and can be quickly recovered from when a patient is in urgent need.

Mesenchymal stem cells can transdifferentiate into corneal epithelial cells which are used to restore experimental limbal stem cell deficiency in rabbits [200]. More often, modulatory effect of rat bone marrow mesenchymal stem cells (MSC) on human corneal epithelial cells (HCE-T) is stimulated with pro-inflammatory cytokines interferon gamma (IFN- $\gamma$ ) and tumor necrosis factor alpha $(\mathrm{TNF}-\alpha)$ [201]. Further, different factors, such as TGF- $\beta$, IL-10, IDO, PGE-2, sHLA-G5, HO, and Galectin-3, secreted by MSCs, induce cell to cell interaction and generate immunomodulatory effects on innate and adaptive cells of the immune system [197]. Both cell-cell contact inhibition and transforming growth factor-beta2 (TGF- 32 ) in aqueous humor may be responsible for maintaining human endothelial cells in a non-replicative state in vivo [202]. Contrary to this, human limbal explants can be generated in a cholera toxin-free medium with no feeder cell layer [203]. Superficial limbal explants are also used to promote the surgical treatment of fungal keratitis [204]. Neural colonies (neurospheres) can be generated from adult corneal limbus in vitro [205]. Defective corneal development causes secondary defects in lens due to defective migration of peri-ocular $\mathrm{Nrp} 2+$ neural crest/mesenchymal cells [206].

Human corneal epithelium contains self-renewal cells and can be maintained by setting a regular microenvironment in the limbus. These cells nurture in a specific microenvironment or limbal cell niche that can generate stromal cells similar to fibroblasts [207]. Under a suitable micro-niche bone marrow mesenchymal stem cells (MSCs) transdifferentiate into corneal epithelial cells and are used in limbal stem cell deficiency (LSCD) [208]. Limbal stem cell deficiency (LSCD) may also relate to aniridic keratopathy (AK) with minimally affected irides [209]. However, destruction of the limbal epithelium barrier is the most important mechanism of pterygium formation [205] and both primary and secondary corneal endothelial decompensation leads to stromal edema, corneal opacity and loss of visual activity [205]. These cells found in basal layer of the limbus that found in a narrow transition zone segregates the peripheral cornea from the adjacent conjunctiva [210]. It is also required for vascular regeneration of corneal and retinal cells [211]. MSCs induction by CSCs (corneal stem cells) that transdifferentiate into corneal epithelial cells also needs presence of fibroblast growth factor 2 and transforming growth factor $\beta$ for maintain microenvironment to form endothelial-mesenchymal transition (EnMT). This endothelial wound-healing is also maintained by cell migration toward artificial wound defects mediated by p38 and c-Jun N-terminal kinase [212]. There occurs potential difference in fibroblast phenotype across the anterior segment of the human eye because of certain factors that support the regenerative function of human limbal epithelial progenitor cells (LEPs) during wound healing [213].

Mesenchymal stem cells (MSCs) are also isolated from the placenta, specifically from the amniotic membrane. These are used to treat corneal alkali burn and the reconstruction of the corneal surface. Thus amniotic membrane has been clinically applied as a therapeutic material in wound covering and corneal surface reconstruction. Ceratin other factors such as Sox2, Oct-4 and Nanog are also required for AMSCs (amniotic membrane stem cells) differentiation into neuronal-like cells. These are a promising source of stem cells and are extensively used in the field of regenerative medicine [214]. Meanwhile after mesenchymal stem cell transplantation expression of ABCG-2, $\beta(1)$-integrin and connexin 43 is also required to maintain their stem cell character so that they can transdifferentiate into epithelial progenitor cells. MSCs conditioned media was found to inhibit the wound healing activities of corneal stromal fibroblasts in vitro. In addition, putative factors secreted by MSC could be developed for therapeutic use in corneal repair [215]. In Moreover, colonization efficiency of PEA-based copolymers in combination with extracellular matrix coatings has been evaluated in vitro for derivatization of mesenchymal stem cells from human adipose tissue (h-ADASC). Further, feasibility of adipose-derived mesenchymal stem cells (ADMSCs) that differentiate into corneal epithelium-like cells after transfection with Pax6 gene is also being checked [39]. Macroporous membranes composed of the optimal PEA subtypes (poly(ethyl acrylate) and coating proteins are tested after implanting them inside rabbit cornea [216].

MSCs are promising candidates for immunomodulatory therapy and are being tested successful in several organ transplant rejection models [217]. These act as bioreactors of soluble factors which promote tissue regeneration in damaged tissues. These (MSC) cells perform distinct functions such as prompt wound healing, anti-inflammatory, immunoregulatory capacity and elicit immunosuppressive effects in a number of situations. These are immunoprivileged cells, which display low expression of major histocompatibilty complex (MHC-II) and its costimulatory molecules on cell surface. These cells also interfere in different immune pathways to respond by means of direct cell-to-cell interactions and soluble factor secretion [218]. MSCs are also used for treatment of many ocular diseases, such as corneal diseases, uveitis and retinal diseases [219]]. These are most appropriate candidates 
used in cell therapy and potentially used in veterinary regenerative medicine [220].

Mesenchymal stem cells (MSCs) reside in different body tissues and can be obtained from bone marrow, skeletal muscle, dental pulp, bone, umbilical cord and adipose tissue. These cells can form many cell types such as retinal pigment epithelial cells, corneal keratocytes, osteosarcoma and microvascular endothelial cells by exposing them with different physical chemical factors [221]. Mesenchymal stem cells generate potential beneficial factors that make corneal recovery possible. For this purpose MSCs are seeded on a xenogeneic acellular corneal matrix (ACM) in vitro [219] in a suitable microenvironment. The secreted corneal matrix can be used as a substitute for healing corneal wounds [219]. However, post-operative injection of MSCs could inhibit keratoplasty rejection and prolong the corneal allografts survival in a rat model [219].

Allogeneic cultivated limbal epithelial cells are also transplanted into the recipient eye for restoration of visual defects [222] but they need human amniotic membrane as a carrier. Limbal basal epithelial cells serve as niche cells and assist in generation of various cell progenitors. These form diverse cell types which participate in tissue regeneration and corneal wound healing [201]. However, by nurturing these cells under a suitable biological niche these cells could facilitate corneal epithelial regeneration by providing physical support and chemical signaling [201]. Similar, niche also plays critical role in maintaining stem cell differentiation [223]. Adipose tissue derived mesenchymal stem cells show expression of epithelial markers i.e. CD34, CD90, p63, and ABCG2 and CK3/76, CK12, CK76, CK19, and CK1/5/10/14. These also display expression of putative stem cell markers (CD90, ABCG2, and p63) and cytokeratins (CK12 and CK76). These markers provide selfrenewal capacity and intrinsic plasticity to adipose tissue derived mesenchymal stem cells. After cellular differenetiation these cells acquire some epithelial-like characteristics. Due to their high self renewal capacity adult ADSCs (adipose-derived stem cells) cells are used as a potential source for cell therapy in ocular surface regeneration [224]. Stromal cell secreted soluble factors/ growth factors are used to establish micro-niche of corneal epithelial stem cells. But in in vitro cultures epithelial cells organize to form epithelial clusters and make sheet like structures which upon dislodging by gentle enzymatic digestion separate into transplantable cell population [203]. Limbal stromal niche cells heterogeneously express embryonic stem cell (SC) markers [225]. Limbal stem cells are used for restoration of corneal transprency. Corneal limbal stromal progenitor cells are used as autologous cell source to produce functional neurons [226].

Corneal allotransplantations are also done by intravenous infusion of human MSCs (hMSCs) [227]. These cells are derived from homing of human umbilical cord blood and are used for injured or diseased corneal endothelium [179]. MSCs are also derived from human amniotic membranes ex-utero for corneal therapy [228]. MSCs are also used as alternative for corneal grafts and a biological matrix for limb cells cultures used to regenerate the corneal lesions. These cells remain viable and reconstruct a stable ocular surface. Similarly, cultivated oral mucosal epithelial transplantation (COMET) is used for treatment of eyes with total limbal stem cell deficiency [229]. Hence, normal regeneration and epithelialization of the corneal surface is highly important for obtaining a satisfactory long-term outcome, and lower down the transplantation failures and other complications [229]. By using explants cultures epithelial-mesenchymal transition can be made for intrastromal transplantations [230].

Human limbus tissue is used for deriving epithelial stem cells, and stromal fibroblast-like stem cells [231]. These cells secrete and organize a thick stroma-like extracellular matrix in response to different substrata, but neither cell type organizes matrix on tissue-culture polystyrene [232]. Both human corneal stromal stem cells (hCSSCs) and human corneal fibroblasts (hCFs) are used for generation of human corneal stromal tissue. Their culture is maintained on a highly-aligned fibrous substrate made up of poly (ester urethane) urea. These cells are also maintained in the serum-free medium supplemented with FGF-2 $(10 \mathrm{ng} / \mathrm{mL})$ and TGF- $\beta 3(0.1 \mathrm{ng} / \mathrm{mL})$. Human corneal stromal stem cells (hCSSCs) are successfully differentiated into keratocytes which form multilayered lamellae with orthogonally-oriented collagen fibrils [233]. Moreover, for cellular differentiation of stem cells progenitors need induction from certain factors that are added in culture media [55].

Multipotent mesenchymal stromal cells (MSCs) found in number of tissues. Mesenchymal stem cells (MSCs) are used to contruct ocular surface and are subconjunctivally administered on corneal wound healing in the acute stage of an alkali burn [234]. These are widely used in tissue engineering, immunology, gene therapy, and oncology [235]. MSCs significantly accelerate corneal wound healing and attenuate inflammation and reduce CNV (corneal neovascularization) in alkaline-burned corneas. These cells influence cell proliferation and growth factor expression of corneal limbal epithelial cells (LECs) in vitro [236]. Further, down-regulation of MIP- $1 \alpha$, TNF- $\alpha$ and VEGF influence cell proliferation [234]. Similarly, SDF- $1 \alpha$-induced progenitor cell recruitment and macrophage VEGF production plays critical role in the experimental corneal neovascularization [237]. In addition, systemic administration of adult stem/progenitor cells (MSCs) reduces inflammatory damage to the cornea without engraftment and primarily by secretion of TNF- $\alpha$ stimulated gene/protein 6 [238].

Retinal pigment epithelial cells and photoreceptor progenitors (lens cells) are used for treatment of retinal diseases mainly for treatment of cataract. Retinal pigment epithelial and lens cells are derived from non optic retinal progenitor-like cells. These cells display similar cell surface markers [239]. A rare population of pigmented cells derived from retinal stem cell is also identified in the ocular ciliary body (CB) of adult mammals. These cells clonally proliferate and expand to generate pigmented sphere colonies (PSC) in vitro and form epithelial progenitor-like cells [240]. Embryonic stem cell using stromal cell-derived induce cellular proliferation both in vitro and in vivo. Similarly, BM cell types may infiltrate into injured and/or diseased tissues and subsequently differentiate to form phenotypes of residential cells when injected. These cells are also used to repair damaged tissue sending via circulation to generate a keratocyte phenotype [237].

\section{Tissue bioengineering}

Bioengineered corneal tissues are used as prosthetic devices for replacement of the cornea and restoration of its functions. Though there are difficulties of immune rejection and shortage of organ 
supply for corneal transplantation. Besides, natural keratoplasty, artificially developed cornea is also used to replace damaged one but it shows low biocompatibility. There is an increasing demand of bioenginreed corneal tissues for surface reconstruction and transplantation purposes. These are used with tissue-engineered hydrogels which assist in fast regeneration. Hence, to meet out the shortage of donor corneas for transplantation, particularly in developing countries, bioengineered corneal tissues are used in form of explants for tissue therapy. For mass production of low-cost bioengineered corneas new methods are developed and standardized. These corneas attribute near about similar transparency and compatibility to natural corneas and with host cells. BPCs (bioengineered prosthetic corneas) fabricated into hydrogel corneal implants provide over $90 \%$ transparency and four-fold increase in strength and stiffness compared with previous versions [55]. These tissue engineered corneal transplantations have shown very high success to treat blinding diseases [241].

Further, bioengineering technology has evolved new scaffolds/ biomaterials which are used in reconstructing corneal epithelium. However, for promoting interactions between neurons and corneal tissue co-culture methods are also developed. More specifically, collagen vitrigel (CV) is used for reconstructing corneal epithelium in the stromal wound and limbal stem cell deficiency (LSCD) [242]. It is also is used as a scaffold material for for hLEC (Human Lymphatic Endothelial Cells) transplantation without having complications [242]. It supports corneal epithelial differentiation and prevents epithelial hypertrophy. Similarly, nanofibers prepared from copolymer PA6/12 represent a convenient scaffold (Table 3) for growth of LSCs (limbal stem cells) and MSCs and transfer to treat SC deficiencies and various ocular surface injuries [243]. Moreoften, copolymer PA6/12 nanofibers displays stability in aqueous solutions, biocompatibility as good matrix that supports growth of LSCs (limbal stem cell) [243]. Similarly, Bombyx mori silk fibroin is also used as a substrate for human limbal epithelial (L-EC) and stromal cell cultivation. 3D engineered limbus constructed from B. mori silk fibroin, showed potential benefits in corneo-limbal tissue regeneration [182]. Dual-layer fibroin scaffolds are also prepared by using L-EC and L-MSC secreted matrix and polylactic-co-glycolic acid (PLGA)(Table 3) for repairing corneal stromal defects [179].

Corneal stroma is an avascular connective tissue that is characterized by layers of highly organized parallel collagen fibrils which are mono-disperse in diameter with uniform local interfibrillar spacing. Natural corneal stroma is used as an optimal substrate to construct a natural corneal equivalent to repair eye defects. For this purpose human corneal epithelium is cultured from donor limbal explants on corneal stromal discs that are prepared by FDA approved Horizon Epikeratome system. More specifcally, autologous rASCs (autologous rabbit adipose derived stem cells) are used as cell source for corneal stromal restoration. Mainly autologous rASCs-PLGA constructed corneas have been developed by following tissue engineering methods. These are transparent and without corneal neovascularization [179]. Adipose-derived stem cells (ADSC) express keratocyte-specific phenotypic markers and express corneal-specific matrix components. These cells are cultivated in controlled conditions to support and induce differentiation to form keratocytes [244]. ADSC (adipose derived stem cells) are potentially used in corneal cell therapy and tissue engineering [245]. Similarly, human bone marrow mesenchymal stem cells
(hMSC) are allowed to differentiate into corneal epithelial-like cells after induction. These cells are also used in corneal tissue engineering [56]. Thus, bioengineered spatially complex, collagenbased nano-structured constructs are used for corneal repairing and regeneration [246]. Similarly, bioengineered synthetic corneal tissue derived from corneal stromal stem cells of human origin is also used as a quality biomaterial for corneal reconstruction [247].

Corneal epithelium is used to make tissue-engineered human undifferentiated immature dental pulp stem cells (hIDPSC) sheet and to make reconstructs for transplantation in vitro by maintaining limbal stem cells cultured onto human keratoplasty lenticules (HKLs). Thin collagen matrix and fibroblast-like cells are used in keratoplasty mainly in repairing of retrocorneal membranes (RCMs). HKL is a suitable scaffold material to obtain natural corneal graft for clinical purposes [248]. It induces proliferation, express differentiation markers. It binds to the underlying stroma with no alterations in clonogenic potential. HKLs allow cell growth with no feeder layers, and freeze dried, to preserve integrity and viability of stromal keratocytes [248]. Hevin is a matricellular protein that is used in tissue repair and remodeling via interaction with the surrounding extra cellular matrix (ECM) proteins [249]. Hevin is transiently expressed in the IrrPTK-injured corneas. Its loss predisposes aberrant wound healing and generates severe chronic inflammation and stromal fibrosis. Hevin plays a pivotal role in the corneal wound healing [249]. Electrospin is used for making constructs using rabbit limbal epithelial and stromal cells [56]. It is a biodegradable membrane made up of poly (lactic-co-glycolic acid) 50:50, which incorporates the features of the underlying microfabricated structures. More recently, tissue-engineered hemicornea is also used for therapeutic purpose in pateints which show total limbal stem cell deficiency [176].

Tissue-engineered cell sheets are used for ocular surface reconstruction in animal models mainly having total limbal stem cell deficiency (LSCD) [250]. For designing new tissue engineering scaffolds and long-term success of implants complete regulatory information is needed on cell signaling after damaging ocular surface in the experimental animals [43]. In experimental animal models cornea is damaged by a variety of clinical, chemical, mechanical, and thermal injuries. However, to prepare tissue engineered corneal substitutes (TEC) for treatment of corneal surface defects induced bone marrow mesenchymal stem cells (BMSCs) of corneal lineage are used [251]. In addition, carrier materials such as collagen, fibrin, siloxane hydrogel, poly( $\varepsilon$-caprolactone), gelatin-chitosan, silk fibroin, keratin, poly(lactide-co-glycolide), polymethacrylate, hydroxyethylmethacrylate and poly(ethylene glycol) (Table 3) are potentially used for treatment of limbal stem cell deficiency [252]. Corneal reconstruction is among the most effective methods for curing clinical disorders [163].

Stem cells are also used to generate neogenetic structure from a lineage of bone marrow-derived mesenchymal stem cells [253]. Today nonbiological corneal substitutes such as poly (ethyl acrylate) (PEA)-based copolymers, extracellular matrix-protein coating are used for increasing the survival rate of grafting tissues. Colonization with adipose-derived mesenchymal stem cells has also increased the survival rate of grafts. In addition, for obtaining good results and longer survival human adipose tissue derived mesenchymal stem cells (h-ADASC) and PEA-based copolymers are used in combination with extracellular matrix coatings and 
macroporous membranes composed of the optimal PEA subtypes and coating proteins. PEA with low hydroxylation as a scaffold also gives good results [218] (Table 3).

Human corneal stromal stem cell (hCSSCs) when cultured on biodegradable poly(ester urethane)urea (PEUU) get differentiated to keratocytes. These are also used to produce abundant matrix that helps in organization of the transparent connective tissue of the corneal stroma by differentiated keratocytes. Similarly, human mesenchymal stem cells (MSC), cultured without any feeder layer (NF) show derivatization of cornea epithelial that is used for making constructs mainly for xenografts [254]. MSCs cultured on nanofiber scaffolds provide protection from formation of toxic peroxynitrite. It lowers the apoptotic cell death and decreased matrix metalloproteinase and pro-inflammatory cytokine production which lower down corneal inflammation as well as neovascularization and significantly accelerated corneal healing [255]. Corneal epithelial stem cells (SCs) need more adaptable niche to differentiate into limbal palisades of Vogt, located between the cornea and the conjunctiva. But limbal stem cells also require close physical association with their native NCs via SDF-1/CXCR4 signaling for appropriate differentiation [230]. However, for management of corneal limbal stem cell deficiency Boston type I keratoprosthesis is followed [256]. Prior to CLSC (Cord Lining Stem Cells) transplantation anti-lymphangiogenic treatment is also required [57]. Surface treatment to a biomaterial surface modifies cell type and accelerates the cell growth [256]. However, for generation of complex organ structures mainly any eye component it will require the intricate orchestration of multiple cellular interactions. Few genes linked to Lhx2's function in the expansion and patterning of progenitor cells have been identified [257].

\section{Conclusion}

Neonatal eye defects are seen at global level and notified as important congenital eye defects. There neonatal visual defects either developmental, mainly secondary to genetic conditions or due to use of drugs, alcohol or maternal blood sugar. There are certain genetic disorders and defects of eye lid, cornea, iris and pupil, choroid and retina, visual nerve which are a leading cause of visual impairment in children. There are also problems of poor vision with no apparent cause. Stem cells possess enormous potential to replace defective tissues and treat various pathological conditions. For tissue repairing and its regeneration artificial cell systems have been developed for construction of tissues both directly by providing repair cells and indirectly by modulating inflammatory and immune responses. Transplantation of keratoplasts, epithelial sheets, biomatrix and new biocompatible scaffold materials are also essentially required for restoration of eye defects. These scaffolds are used in corneal transplantation to treat blinding diseases like Limbal stem cell deficiency (LSCD). Few important silk fibroin scaffolds, poly (ethyl acrylate) (PEA), polylactic-co-glycolic acid (PLGA) are bioenginnered are used as important biomaterials for repairing corneal stromal defects. Further, for good therapeutic successes major reasons of neonatal eye defects such as chromosomal abnormalities, genetic mutations, infection, and prenatal drug exposure should be established in animal models. There was felt an urgent need of new matrix designs, scaffold materials and extracellular matrix remodeling for neonatal eye defects. Use of appropriate nutritients and drugs were found somewhat preventable and to reduce congenital malformations. An earlier red reflex screening and physical examination of newborns is highly suggestive to short out ophthalmologic abnormality and to reduce mental stress and pain. Corneal pathological effects related to one or all of the corneal layers that produce corneal opacity can be removed by using stem cells. Moreover, by transplantation of stem cell progenitors, epithelial stem cells can be generated for sequestering towards the injury sites for repairing of eye defects in adults. There is an increasing demand of human corneal tissues for surface reconstruction and transplantation. There is a worldwide donor tissue shortage and many allogeneic grafts are eventually rejected. However, to fulfill demand of corneal tissue grafts new innovative methods are being developed to supplement tissue donation. Due to insufficient cornea donation and inherent artificial lens problems, alternative treatment strategies based on stem cell transplantations become boon for visually impaired new borns. For cell replacement therapy and transplantation for effective corneal regeneration and reconstruction stem cells induced to express markers consistent with multipotency are successfully used. Consequently, efforts should be to cutdown long-term vision impairments in neonates for quick restoration and improving quality of their life. Hence, for stepwise management and therapeutics of eye related defects, identification of disorder based appropriate and authentic biomarkers are to be explored. All multidisciplinary approaches should apply to treat the neonatal patients having eye defects. Lastly, for cognitive and behavioral assessments neonates and infants are recommended adequate opthalmological and neuropsychological support for their rehabilitation. An early diagnosis and prompt treatment may help patients with compressive and toxic ophthalmic-neuropathies.

\section{Acknowledgements}

Author is thankful to Prof. Ashok Kumar, Vice Chancellor, DDU Gorakhpur University, Gorakhpur for his kind support.

\section{References}

[1]. Holmström GE, Källen K, Hellström A., Jakobsson PG., Serenius, F, et al. (2014) Ophthalmologic outcome at 30 months' corrected age of a prospective Swedish cohort of children born before 27 weeks of gestation: the extremely preterm infants in Sweden study. JAMA Ophthalmol. 132(2):1829.

[2]. Li. LH, Li N., Zhao JY., Fei P., Zhang GM., et al. (2013) Findings of perinatal ocular examination performed on 3573, healthy full-term newborns. Br J Ophthalmol 97(5):588-91.

[3]. Kim, M., Lee SC., Lee SJ.( 2013) Spontaneous corneal perforation in an eye with Peters' anomaly. Clin Ophthalmol 7:1535-7.

[4]. Brancati F., Dallapiccola B., Valente EM. (2010) Joubert Syndrome and related disorders. Orphanet J Rare Dis 5:20.

[5]. Sawardekar SS., Zaenglein AL ( 2011) Ankyloblepharon-ectodermal dysplasia-clefting syndrome: a novel p63 mutation associated with generalized neonatal erosions. Pediatr Dermatol 28(3):313-7.

[6]. Hirata A., Mine T. (2013) A simple and easy method using rigid endoscope to detect iridocorneal and keratolenticular adhesions in peters' anomaly. Case Rep Ophthalmol 4(3):238-42.

[7]. Piotrowski JT, Diehl NN., Mohney BG. (2010) Neonatal dacryostenosis as a risk factor for anisometropia. Arch Ophthalmol 128(9):1166-9.

[8]. Medsinge A, Speedwell L., Nischal KK. ( 2014) Defining success in infant penetrating keratoplasty for developmental corneal opacities. Am Orthopt J. 64:81-8.

[9]. Posey JE., Dariya V., Edmonds JL., Lee EI., Probst FJ., et al. (2014) Syngnathia and obstructive apnea in a case of popliteal pterygium syndrome. Eur J Pediatr 173(12):1741-4.

[10]. Lewis ML. (2014) A comprehensive newborn exam: part I. General, head and neck, cardiopulmonary. Am Fam Physician. 90(5):289-96.

[11]. Yeom W, Kim MN, Choi SJ, Oh SY, Roh CR, et al. (2015) Hyperplastic primary vitreous with hemorrhage manifested as a hyperechoic mass in the 
fetal orbit by prenatal ultrasound in a case of isolated unilateral microphthalmia. Obstet Gynecol Sci. 58(4):309-13.

[12]. Yazıcı B., Toka F., Cömez AT. (2014) Anatomical characteristics and surgical treatment of bilateral congenital upper eyelid entropion in an infant with neonatal progeroid syndrome. Ophthal Plast Reconstr Surg 30(6):e164-6.

[13]. Wegner, A., Schmidt, KG ( 2013) The incidence of retinal haemorrhages and their implications. Br J Ophthalmol 97(8):1082-3.

[14]. Angemi JA., Zuccotti JC. ( 2012) Joubert syndrome: report of four adult siblings affected. Rev Neurol. 54(10):609-12.

[15]. Nishri D, Edvardson S, Lev D, Leshinsky-Silver E, Ben-Sira L, et al. (2014) Diagnosis by whole exome sequencing of atypical infantile onset Alexander disease masquerading as a mitochondrial disorder. Eur J Paediatr Neurol. 18(4):495-501.

[16]. Quina LA., Kuramoto T., Luquetti D, Cox TC., Serikawa T, et al. ( 2012) Deletion of a conserved regulatory element required for $\mathrm{Hmx} 1$ expression in craniofacial mesenchyme in the dumbo rat: a newly identified cause of congenital ear malformation. Dis Model Mech 5(6):812-22.

[17]. Kennedy DP., Chandler JW., McCulley JP. (2015) Ocular surface involvements in ectrodactyly-ectodermal dysplasia-cleft syndrome. Cont Lens Anterior Eye. 38(3):228-31.

[18]. Biancheri R., Zara F., Bruno C., Gazzerro E., Rossi A., etal.( 2008) Hypomyelination and congenital cataract. University of Washington, Seattle; 1993-2015.

[19]. Kurihara T., Kubota Y., Ozawa Y., Takubo K., Noda K., et al. (2010) von Hippel-Lindau protein regulates transition from the fetal to the adult circulatory system in retina. Development 137(9):1563-71.

[20]. Kivistö K., Tupola S., Kivitie-Kallio S (2015) Prenatally buprenorphineexposed children: health to 3 years of age. Eur J Pediatr. 174(11):1525-33.

[21]. de Araujo AL, Gomes JÁ. (2015) Corneal stem cells and tissue engineering: Current advances and future perspectives. World J Stem Cells.7(5):806-14.

[22]. Medsinge A., Speedwell L., Nischal KK. (2014) Defining success in infant penetrating keratoplasty for developmental corneal opacities. Am Orthopt J 64:81-8.

[23]. Zepeda-Romero LC, Oregon-Miranda AA, Lizarraga-Barrón DS, Gutiérrez-Camarena O, Meza-Anguiano A, et al., (2013) Early retinopathy of prematurity findings identified with fluorescein angiography. Graefes Arch Clin Exp Ophthalmol 251(9):2093-7.

[24]. Dursun I., Jakubowska-Doğru E., van der List D., Liets L.C., Coombs JL., et al. (2011) Effects of early postnatal exposure to ethanol on retinal ganglion cell morphology and numbers of neurons in the dorsolateral geniculate in mice. Alcohol Clin Exp Res 35(11):2063-74.

[25]. Maldonado R.S., Freedman SF., Cotten CM., Ferranti JM., Toth CA. (2011) Reversible retinal edema in an infant with neonatal hemochromatosis and liver failure. J AAPOS. 15(1):91-3.

[26]. Meuwissen ME., Mancini GM (2012) Neurological findings in incontinentia pigmenti; a review. Eur J Med Genet. 55(5):323-31

[27]. Hamilton R, McGlone L, MacKinnon JR, Russell HC, Bradnam MS, et al. (2010) Ophthalmic, clinical and visual electrophysiological findings in children born to mothers prescribed substitute methadone in pregnancy. $\mathrm{Br}$ J Ophthalmol 94(6):696-700.

[28]. Walsh JE., Bergmanson JP. (2011) Does the eye benefit from wearing ultraviolet-blocking contact lenses? Eye Contact Lens 37(4):267-72.

[29]. Wenzel PL., Chong JL., Sáenz-Robles MT., Ferrey A., Hagan JP, et al. ( 2011) Cell proliferation in the absence of E2F1-3. Dev Biol 351(1):35-45.

[30]. Oschman A., Murthy V., Kollipara R., Kenneth Lord R., Oluola O. (2013) Intravitreal ganciclovir for neonatal cytomegalovirus-associated retinitis: a case report. J Perinatol. 33(4):329-31.

[31]. Cluver C, Meyer R, Odendaal H, Geerts L. (2013) Congenital rubella with agenesis of the inferior cerebellar vermis and total anomalous pulmonary venous drainage. Ultrasound Obstet Gynecol. 42(2):235-7.

[32]. Hussain S., Asghar I., Sabir MU., Chattha MN, Tarar SH, et al. (2014) Prevalence and pattern of congenital malformations among neonates in the neonatal unit of a teaching hospital. J Pak Med Assoc. 64(6):629-34.

[33]. Oh JY, Yu JM, Ko JH. (2013) Analysis of ethanol effects on corneal epithelium. Invest Ophthalmol Vis Sci. 54(6):3852-6.

[34]. Mussavi M, Asadollahi K, Janbaz F, Mansoori E, Abbasi N (2014) The Evaluation of Red Reflex Sensitivity and Specificity Test among Neonates in Different Conditions. Iran J Pediatr 24(6):697-702.

[35]. Cabrera MT., Freedman SF, Hartnett ME., Stinnett SS., Chen BB. Et al. (2014) Real-time, computer-assisted quantification of plus disease in retinopathy of prematurity at the bedside. Ophthalmic Surg Lasers Imaging Retina. 45(6):542-8

[36]. Wan MJ, VanderVeen DK. (2015) Eye disorders in newborn infants (excluding retinopathy of prematurity). Arch Dis Child Fetal Neonatal Ed. 100(3):F264-9.

[37]. Karimzadeh P., Tabarestani S., Ghofrani M (2011) Hypoglycemia-occipital syndrome: a specific neurologic syndrome following neonatal hypoglyce- mia? J Child Neurol. 26(2):152-9.

[38]. Eventov-Friedman S., Leiba H., Flidel-Rimon O., Juster-Reicher A., Shinwell ES. (2010) The red reflex examination in neonates: an efficient tool for early diagnosis of congenital ocular diseases. Isr Med Assoc J. 12(5):259-61.

[39]. Liu W., Liu Y., Liu H., Luo Y., Xu J. (2014) Differentiation of adipose-derived mesenchymal stem cells after transfection with Pax6 gene. Zhongguo Xiu Fu Chong Jian Wai Ke Za Zhi. 28(8):1004-8.

[40]. Molvaer RK., Andreasen A., Heegaard S., Thomsen JS., Hjortdal J., et al.(2013) Interactive 3D computer model of the human corneolimbal region: crypts, projections and stem cells. Acta Ophthalmol. 91(5):457-62.

[41]. Polisetti N., Zenkel M., Menzel-Severing J., Kruse FE., Schlötzer-Schrehardt U.et al. (2015) Cell Adhesion Molecules and Stem Cell-Niche-Interactions in the Limbal Stem Cell Niche. Stem Cells. 34(1): 203-219.

[42]. Dhouailly D, Pearton DJ, Michon F. (2014) The vertebrate corneal epithelium: from early specification to constant renewal. Dev Dyn. 243(10):122641.

[43]. Holan V., Trosan P., Cejka C., Javorkova E., Zajicova A., et al. ( 2015) A Comparative Study of the Therapeutic Potential of Mesenchymal Stem Cells and Limbal Epithelial Stem Cells for Ocular Surface Reconstruction. Stem Cells Transl Med. 4(9):1052-63.

[44]. Lal I, Panchal BU, Basu S, Sangwan VS. (2013) In-vivo expansion of autologous limbal stem cell using simple limbal epithelial transplantation for treatment of limbal stem cell deficiency. BMJ Case Rep.

[45]. Liu CY, Kao WW (2015) Corneal Epithelial Wound Healing. Prog Mol Biol Transl Sci. 134:61-71.

[46]. Livny E., Livnat T., Yakimov M., Masoud M., Weinberger D, et al.(2013) Effect of erythropoietin on healing of corneal epithelial defects in rabbits. Ophthalmic Res. 50(2):129-33.

[47]. Irani YD, Tian Y. Wang M. Klebe S, McInnes SJ, et al. (2015) A novel pressed porous silicon-polycaprolactone composite as a dual-purpose implant for the delivery of cells and drugs to the eye. Exp Eye Res. 139:123-31.

[48]. Eriş E, Yüksel N, Pirhan D, Karadenizli A, Aslan M, et al. (2016) Evaluation of Effect of Topical Tacrolimus Treatment on Herpetic Stromal Keratitis in a Rat Model. Eye Contact Lens. 42(3):163-70.

[49]. Mellough CB, Collin J, Khazim M, White K, Sernagor E, et al. (2015) IGF1 Signaling Plays an Important Role in the Formation of Three-Dimensional Laminated Neural Retina and Other Ocular Structures From Human Embryonic Stem Cells. Stem Cells. 33(8):2416-30.

[50]. Heermann S, Schütz L, Lemke S, Krieglstein K, Wittbrodt J. (2015) Eye morphogenesis driven by epithelial flow into the optic cup facilitated by modulation of bone morphogenetic protein. Elife. 4 .

[51]. Pinnamaneni N, Funderburgh JL. (2012) Concise review: Stem cells in the corneal stroma. Stem Cells. 30(6):1059-63.

[52]. Hashmani K, Branch MJ, Sidney LE, Dhillon PS, Verma M, etal. (2013) Characterization of corneal stromal stem cells with the potential for epithelial transdifferentiation. Stem Cell Res Ther. 2013;4(3):75.

[53]. Lisch W, Pitz S, Geerling G. (2013) Therapy for systemic metabolic disorders based on the detection of basic corneal landmarks in childhood. Klin Monbl Augenheilkd. 230(6):575-81.

[54]. Ortega I, Ryan AJ, Deshpande P, MacNeil S, Claeyssens F. (2013) Combined microfabrication and electrospinning to produce 3-D architectures forcorneal repair. Acta Biomater. 9(3):5511-20.

[55]. Lin J, Yoon KC, Zhang L, Su Z, Lu R, etal. (2012) A native-like corneal construct using donor corneal stroma for tissue engineering. PLoS One. 7(11):e49571.

[56]. Wu J, Du Y, Watkins SC, Funderburgh JL, Wagner WR (2012) The engineering of organized human corneal tissue through the spatial guidance of corneal stromal stem cells. Biomaterials. 33(5):1343-52.

[57]. Zhang H, Brown KD, Lowe SP, Liu GS, Steele D, et al. (2014) Acrylic acid surface-modified contact lens for the culture of limbal stem cells. Tissue Eng Part A. 20(11-12):1593-602.

[58]. Noh JW, Kim JJ, Hyon JY, Chung ES, Chung TY, et al. (2015) Stemness characteristics of human corneal endothelial cells cultured in various media. Eye Contact Lens. 41(3):190-6.

[59]. Lachaud CC, Soria F, Escacena N, Quesada-Hernández E, Hmadcha A, et al. (2014) Mesothelial cells: a cellular surrogate for tissue engineering of corneal endothelium. Invest Ophthalmol Vis Sci. 55(9):5967-78.

[60]. Ding V, Chin A, Peh G, Mehta JS, Choo A. (2014) Generation of novel monoclonal antibodies for the enrichment and characterization of human corneal endothelial cells (hCENC) necessary for the treatment of corneal endothelial blindness. MAbs. 6(6):1439-52.

[61]. Coulson-Thomas VJ, Caterson B, Kao WW. et al. (2013) Transplantation of human umbilical mesenchymal stem cells cures the cornealdefects of mucopolysaccharidosis VII mice. Stem Cells. 31(10):2116-26.

[62]. Hatou S, Yoshida S, Higa K, Miyashita H, et al. (2013) Functional corneal endothelium derived from corneal stroma stem cells of neural crest origin by retinoic acid and Wnt/ $\beta$-catenin signaling. Stem Cells Dev. 22(5):828-39. 
[63]. Riau AK, Mondal D, Yam GH, Setiawan M, Liedberg B, et al. (2015) Surface Modification of PMMA to Improve Adhesion to Corneal Substitutes in a Synthetic Core-Skirt Keratoprosthesis. ACS Appl Mater Interfaces. 7(39):21690-702

[64]. Kobayashi T, Shiraishi A, Hara Y, Kadota Y, Yang L, et al. (2015) Stromalepithelial interaction study: The effect of corneal epithelial cells on growth factor expression in stromal cells using organotypic culture model. Exp Eye Res. 135:109-17.

[65]. Alio del Barrio JL, Chiesa M, Garagorri N, Garcia-Urquia N, FernandezDelgado J, et al. (2015) Acellular human corneal matrix sheets seeded with human adipose-derived mesenchymal stem cells integrate functionally in an experimental animal model. Exp Eye Res. 132:91-100.

[66]. Fukuta M, Nakai Y, Kirino K, Nakagawa M, Sekiguchi K, etal. (2014) Derivation of mesenchymal stromal cells from pluripotent stem cells through a neural crest lineage using small molecule compounds with defined media. PLoS One. 9(12):e112291.

[67]. Greene CA, Chang CY, Fraser CJ, Nelidova DE, Chen JA, et al. (2014) Cells from the adult corneal stroma can be reprogrammed to a neuron-like cell using exogenous growth factors. Exp Cell Res. 322(1):122-32.

[68]. Xie LX. (2010) Advances in basic and clinical corneal research. Zhonghua Yan Ke Za Zhi. 46(10):883-7.

[69]. Erclik T, Hartenstein V, McInnes RR, Lipshitz HD. (2009) Eye evolution at high resolution: the neuron as a unit of homology. Dev Biol. 332(1):70-9.

[70]. Espandar L, Caldwell D, Watson R, Blanco-Mezquita T, Zhang S, et al. (2014) Application of adipose-derived stem cells on scleral contact lens carrier in an animal model of severe acute alkaline burn. Eye Contact Lens. 40(4):243-7.

[71]. Chao JR, Bronner ME, Lwigale PY (2013) Human fetal keratocytes have multipotent characteristics in the developing avian embryo. Stem Cells Dev. 22(15):2186-95.

[72]. Hertsenberg AJ, Funderburgh JL. (2015) Generation of Corneal Keratocytes from Human Embryonic Stem Cells. Methods Mol Biol. 1341:285-94 [Epub ahead of print]

[73]. Syed-Picard FN, Du Y, Lathrop KL, Mann MM, Funderburgh ML, et al. (2015) Dental pulp stem cells: a new cellular resource for corneal stromal regeneration. Stem Cells Transl Med. 4(3):276-85.

[74]. Villatoro AJ, Fernández V, Claros S, Rico-Llanos GA, Becerra J, et al. (2015) Use of adipose-derived mesenchymal stem cells in keratoconjunctivitis sicca in a canine model. Biomed Res Int. 2015:527926.

[75]. Branch MJ, Yu WY, Sheridan C, Hopkinson A. (2015) Isolation of adult stem cell populations from the human cornea. Methods Mol Biol. 1235:165-77.

[76]. Byun YS, Tibrewal S, Kim E, Yco L, Sarkar J, et al. (2014) Keratocytes derived from spheroid culture of corneal stromal cells resemble tissue resident keratocytes. PLoS One. 9(11):e112781.

[77]. Macdonald EC, Gregory ME, Lockington D, Kennedy A, Roberts F, et al. (2010) Observation of the in vivo movement of host keratocytes into donor tissue following corneal graft; a novel technique. Br J Ophthalmol. 94(6):790-4.

[78]. McIntosh Ambrose W, Schein O, Elisseeff J. (2010) A tale of two tissues: stem cells in cartilage and corneal tissue engineering. Curr Stem Cell Res Ther. 5(1):37-48.

[79]. Na KS, Mok JW, Joo CK. (2015) Ex vivo human corneal epithelial cell expansion from a xeno-feeder-free system. Ophthalmic Res. 53(4):217-24.

[80]. Eberwein P, Reinhard T.( 2015) Concise reviews: the role of biomechanics in the limbal stem cell niche: new insights for our understanding of this structure. Stem Cells. 33(3):916-24.

[81]. Saburina IN, Kolokoltsova TD, Kopaev SY, Zurina IM, Borzenok SA. (2014) Experience of culturing anterior epithelial corneal cells from human eye ball. Patol Fiziol Eksp Ter. (4):120-6

[82]. Nieto-Miguel T, Galindo S, Reinoso R, Corell A, Martino M, et al. (2013) In vitro simulation of corneal epithelium microenvironment induces a cornealepithelial-like cell phenotype from human adipose tissue mesenchymal stem cells. Curr Eye Res. 38(9):933-44.

[83]. Harkin DG, Foyn L, Bray LJ, Sutherland AJ, Li FJ, et al. (2015) Concise reviews: can mesenchymal stromal cells differentiate into corneal cells? A systematic review of published data. Stem Cells.33(3):785-91.

[84]. Ljubimov AV, Saghizadeh M. (2015) Progress in corneal wound healing. Prog Retin Eye Res. 49:17-45.

[85]. Numata R, Okumura N, Nakahara M, Ueno M, Kinoshita S, et al. (2014) Cultivation of corneal endothelial cells on a pericellular matrix prepared from human decidua-derived mesenchymal cells. PLoS One. 9(2):e88169.

[86]. De Miguel MP, Fuentes-Julián S, Blázquez-Martínez A, Pascual CY, Aller MA, et al. (2012) Immunosuppressive properties of mesenchymal stem cells: advances and applications. Curr Mol Med. 12(5):574-91.

[87]. Basu S, Taneja M, Narayanan R, Senthil S, Sangwan VS. (2012) Short-term outcome of Boston Type 1 keratoprosthesis for bilateral limbal stemcell de- ficiency. Indian J Ophthalmol. 60(2):151-3.

[88]. Acar U, Pinarli FA, Acar DE, Beyazyildiz E, Sobaci G, et al.(2015) Effect of allogeneic limbal mesenchymal stem cell therapy in corneal healing: role of administration route. Ophthalmic Res. 53(2):82-9.

[89]. Casaroli-Marano RP, Nieto-Nicolau N, Martínez-Conesa EM. (2013) Progenitor cells for ocular surface regenerative therapy. Ophthalmic Res. 49(3):115-21

[90]. Yoon JJ, Wang EF, Ismail S, McGhee JJ, Sherwin T. (2013) Sphere-forming cells from peripheral cornea demonstrate polarity and directed cell migration. Cell Biol Int. 37(9):949-60.

[91]. Wu J, Du Y, Mann MM, Yang E, Funderburgh JL, et al. (2013) Bioengineering organized, multilamellar human corneal stromal tissue by growth factor supplementation on highly aligned synthetic substrates. Tissue Eng Part A. 19(17-18):2063-75.

[92]. Klimova L, Kozmik Z. (2014) Stage-dependent requirement of neuroretinal Pax6 for lens and retina development. Development. 141(6):1292-302.

[93]. Xi JH, Bai F, Gross J, Townsend RR, Menko AS, et al. (2008) Mechanism of small heat shock protein function in vivo: a knock-in mouse model demonstrates that the R49C mutation in alpha A-crystallin enhances protein insolubility and cell death. J Biol Chem. 283(9):5801-14.

[94]. Ahmed H, Vasta GR. (2008) Unlike mammalian GRIFIN, the zebrafish homologue (DrGRIFIN) represents a functional carbohydrate-binding galectin. Biochem Biophys Res Commun. 371(3):350-5.

[95]. Hogerheyde TA, Stephenson SA, Harkin DG, Bray LJ, Madden PW, et al.( 2013) Evaluation of Eph receptor and ephrin expression within the human cornea and limbus. Exp Eye Res. 107:110-20.

[96]. Balenci L, Wonders C, Coles BL, Clarke L, van der Kooy D. (2013) Bone morphogenetic proteins and secreted frizzled related protein 2 maintain the quiescence of adult mammalian retinal stem cells. Stem Cells. 31(10):221830.

[97]. Salero E, Blenkinsop TA, Corneo B, Harris A, Rabin D, et al. (2012) Adult human RPE can be activated into a multipotent stem cell that produces mesenchymal derivatives. Cell Stem Cell. 10(1):88-95.

[98]. Call MK, Grogg MW, Tsonis PA. (2005) Eye on regeneration. Anat Rec B New Anat. 287(1):42-8.

[99]. Purcell P, Oliver G, Mardon G, Donner AL, Maas RL. (2005) Pax6-dependence of Six3, Eya1 and Dach1 expression during lens and nasal placode induction. Gene Expr Patterns. 6(1):110-8.

[100].Perry KJ, Thomas AG, Henry JJ. (2013) Expression of pluripotency factors in larval epithelia of the frog Xenopus: evidence for the presence of cornea epithelial stem cells. Dev Biol. 374(2):281-94.

[101]. Chylack LT Jr, Fu L, Mancini R, Martin-Rehrmann MD, Saunders AJ, et al. (2004) Lens epithelium-derived growth factor (LEDGF/p75) expression in fetal and adult human brain. Exp Eye Res.79(6):941-8.

[102]. Wolosin JM, Budak MT, Akinci MA. (2004) Ocular surface epithelial and stem cell development. Int J Dev Biol. 48(8-9):981-91.

[103]. Zhao H, Yang Y, Partanen J, Ciruna BG, Rossant J et al. (2006) Fibroblast growth factor receptor 1 (Fgfr1) is not essential for lens fiber differentiation in mice. Mol Vis. 12:15-25.

[104]. Aoki H, Hara A, Nakagawa S, Motohashi T, Hirano M, et al. (2006) Embryonic stem cells that differentiate into RPE cell precursors in vitro develop into RPE cell monolayers in vivo. Exp Eye Res. 82(2):265-74.

[105]. Haruta M. (2005) Embryonic stem cells: potential source for ocular repair. Semin Ophthalmol. 20(1):17-23.

[106]. Tsonis PA, Del Rio-Tsonis K. (2004) Lens and retina regeneration: transdifferentiation, stem cells and clinical applications. Exp Eye Res.78(2):161-72.

[107]. Henry JJ. (2003) The cellular and molecular bases of vertebrate lens regeneration. Int Rev Cytol.;228:195-265.

[108]. Shen CN, Burke ZD, Tosh D. (2004) Transdifferentiation, metaplasia and tissue regeneration. Organogenesis. 1(2):36-44.

[109].Imokawa Y, Simon A, Brockes JP.(2004) A critical role for thrombin in vertebrate lens regeneration. Philos Trans R Soc Lond B Biol Sci. 359(1445):765-76.

[110].Vergara MN, Smiley LK, Del Rio-Tsonis K, Tsonis PA .(2009) The alpha1 isoform of the $\mathrm{Na}+/ \mathrm{K}+$ ATPase is up-regulated in dedifferentiated progenitor cells that mediate lens and retina regeneration in adult newts. Exp Eye Res. 88(2):314-22.

[111].Maki N, Tsonis PA, Agata K. (2010) Changes in global histone modifications during dedifferentiation in newt lens regeneration. Mol Vis. 16:1893-

[112].Yang C, Yang Y, Brennan L, Bouhassira EE, Kantorow M, et al. (2010) Efficient generation of lens progenitor cells and lentoid bodies from human embryonic stem cells in chemically defined conditions. FASEB J. 24(9):3274-83

[113]. Firsova NV, Markintantova IuV, Smirnova IuA, Panova IG, Sukhikh GT, et al. (2008) Identification of the OCT4-pg1 retrogene and NANOG gene expression in the human embryoniceye. Izv Akad Nauk Ser Biol. 2:134-8. 
[114].Lad EM, Cheshier SH, Kalani MY.( 2009) Wnt-signaling in retinal development and disease. Stem Cells Dev. 18(1):7-16.

[115].Zhang J, Huang C, Feng Y, Li Y, Wang W.(2012) Comparison of beneficial factors for corneal wound-healing of rat mesenchymal stem cells and corneal limbal stem cells on the xenogeneic acellular cornealmatrix in vitro. Mol Vis. 18:161-73.

[116]. Ho HY, Chang KH, Nichols J, Li M (2009) Homeodomain protein Pitx3 maintains the mitotic activity of lens epithelial cells. Mech Dev. 126(12):18-29.

[117]. Ren S, Liu T, Jia C, Qi X, Wang Y. (2010) Physiological expression of lens $\alpha$-, $\beta$-, and $\gamma$-crystallins in murine and human corneas. Mol Vis. 16:274552 .

[118]. Oka M, Toyoda C, Kaneko Y, Nakazawa Y, Aizu-Yokota E, et al. (2010) Characterization and localization of side population cells in the lens. Mol Vis.16:945-53.

[119]. Yamamoto N, Majima K, Marunouchi T. (2008) A study of the proliferating activity in lens epithelium and the identification of tissue-type stem cells. Med Mol Morphol. 41(2):83-91.

[120]. Bozanić D, Saraga-Babić M. (2004) Cell proliferation during the early stages of human eye development.AnatEmbryol(Berl).208(5):381-8.

[121]. Jong-Hesse YD, Lang GK, Kampmeier J, Lang GE. (2004) Effect of growth factors on the differentiation of porcine lens epithelial cells. Klin Monbl Augenheilkd. 221(3):175-9.

[122]. Boulton M, Albon J. (2004) Stem cells in the eye. Int J Biochem Cell Biol. 36(4):643-57.

[123]. Colitz CM, Whittington A, Carter R, Warren J. (2004) The effects of oxidative stress on telomerase activity and other stress-related proteins in lens epithelial cells. Exp Eye Res. 78(2):235-42.

[124]. Filoni S. (2009) Retina and lens regeneration in anuran amphibians. Semin Cell Dev Biol. 20(5):528-34.

[125]. Nakamura K, Maki N, Trinh A, Trask HW, Gui J, et al.( 2010) miRNAs in newt lens regeneration: specific control of proliferation and evidence for miRNA networking. PLoS One. 5(8):e12058.

[126]. Takács L, Tóth E, Berta A, Vereb G. (2009) Stem cells of the adult cornea: from cytometric markers to therapeutic applications. Cytometry A. 75(1):54-66.

[127]. Collomb E, Yang Y, Foriel S, Cadau S, Pearton DJ.(2013) The corneal epithelium and lens develop independently from a common pool of precursors. Dev Dyn. 242(5):401-13.

[128].Zhou M, Leiberman J, Xu J, Lavker RM. (2006) A hierarchy of proliferative cells exists in mouse lens epithelium: implications for lens maintenance. Invest Ophthalmol Vis Sci. 47(7):2997-3003.

[129].Zhang Y, Overbeek PA, Govindarajan V. (2007) Perinatal ablation of the mouse lens causes multiple anterior chamber defects. Mol Vis. 13:2289-300

[130]. Katikireddy KR, Jurkunas UV. (2015) Limbal Stromal Tissue Specific Stem Cells and Their Differentiation Potential toCorneal Epithelial Cells. Methods Mol Biol. 1341:437-44.

[131].Mengarelli I, Barberi T. (2013) Derivation of multiple cranial tissues and isolation of lens epithelium-like cells from human embryonic stem cells. Stem Cells Transl Med. 2(2):94-106.

[132]. Albert R, Veréb Z, Csomós K, Moe MC, Johnsen EO, et al. (2012) Cultivation and characterization of cornea limbal epithelial stem cells on lens capsule in animal material-free medium. PLoS One. 7(10):e47187.

[133].Li W, Chen YT, Hayashida Y, Blanco G, Kheirkah A, et al. (2008) Downregulation of Pax6 is associated with abnormal differentiation of corneal epithelial cells in severe ocular surface diseases. J Pathol. 214(1):114-22.

[134]. Shiels A, King JM, Mackay DS, Bassnett S. (2007) Refractive defects and cataracts in mice lacking lens intrinsic membrane protein-2. Invest Ophthalmol Vis Sci. 48(2):500-8.

[135]. Hasegawa A, Hisatomi O, Yamamoto S, Ono E, Tokunaga F. (2007) Stathmin expression during newt retina regeneration. Exp Eye Res. 85(4):518-27.

[136].Sjödal M, Edlund T, Gunhaga L. (2007) Time of exposure to BMP signals plays a key role in the specification of the olfactory and lensplacodes ex vivo. Dev Cell. 13(1):141-9.

[137]. Remington SG, Meyer RA. (2007) Lens stem cells may reside outside the lens capsule: an hypothesis. Theor Biol Med Model. 4:22.

[138]. Galal A, Perez-Santonja JJ, Rodriguez-Prats JL, Abad M, Alio J. (2007) Human anterior lens capsule as a biologic substrate for the ex vivo expansion of limbal stem cells in ocular surface reconstruction. Cornea. 26(4):473-8.

[139].López-García JS, García-Lozano I, Rivas L, Martínez-Garchitorena J. (2006) Congenital aniridia keratopathy treatment. Arch Soc Esp Oftalmol. 81(8):435-44

[140].Endo M, Zoltick PW, Chung DC, Bennett J, Radu A, et al. (2007) Gene transfer to ocular stem cells by early gestational intra-amniotic injection of lentiviral vector. Mol Ther. 15(3):579-87.

[141]. Asami M, Sun G, Yamaguchi M, Kosaka M. (2007) Multipotent cells from mammalian iris pigment epithelium. Dev Biol. 304(1):433-46.
[142]. Yoshii C, Ueda Y, Okamoto M, Araki M. (2007) Neural retinal regeneration in the anuran amphibian Xenopus laevis post-metamorphosis: transdifferentiation of retinal pigmented epithelium regenerates the neural retina. Dev Biol. 303(1):45-56

[143]. Slack JM. (2007) Metaplasia and transdifferentiation: from pure biology to the clinic. Nat Rev Mol Cell Biol. 8(5):369-78.

[144]. Yoshida A, Kawano Y, Kato K, Yoshida S, Yoshikawa H, Muta T. et al (2006) Apoptosis in perforated cornea of a patient with graft-versus-host disease. Can J Ophthalmol. 41(4):472-5.

[145].Polisetti N, Zenkel M, Menzel-Severing J, Kruse FE, Schlötzer-Schrehard U. (2015) Cell Adhesion Molecules and Stem Cell-Niche-Interactions in the Limbal Stem Cell Niche. Stem Cells. 34(1): 203-219.

[146]. Mathews S, Chidambaram JD, Lanjewar S, Mascarenhas J, Prajna NV, et al. (2015) In vivo confocal microscopic analysis of normal human anterior limbal stroma. Cornea. 34(4):464-70.

[147]. Chidambaranathan GP, Mathews S, Panigrahi AK, Mascarenhas J, Prajna NV, et al. ( 2015) In vivo Confocal Microscopic Analysis of Limbal Stroma in Patients With LimbalStem Cell Deficiency. Cornea. 34(11):1478-86.

[148].Castro-Muńozledo F. (2013) Review: corneal epithelial stem cells, their niche and wound healing. Mol Vis. 19:1600-13.

[149]. Tsai CL, Chuang PC, Kuo HK, Chen YH, Su WH, et al. (2015) Differentiation of Stem Cells From Human Exfoliated Deciduous Teeth Toward a Phenotype of Corneal Epithelium In Vitro. Cornea. 34(11):1471-7.

[150].Espana EM, Sun M, Birk DE. ( 2015) Existence of Corneal Endothelial Slow-Cycling Cells. Invest Ophthalmol Vis Sci. 56(6):3827-37.

[151].Tovell VE, Massie I, Kureshi AK, Daniels JT (2015) Functional limbal epithelial cells can be successfully isolated from organ culture rims following long-term storage. Invest Ophthalmol Vis Sci. 56(6):3531-40.

[152]. Li H, Dai Y, Shu J, Yu R, Guo Y et al. (2015) Spheroid cultures promote the stemness of corneal stromal cells. Tissue Cell. 47(1):39-48.

[153]. González S, Deng SX. (2013) Presence of native limbal stromal cells increases the expansion efficiency of limbal stem/progenitor cells in culture. Exp Eye Res. 116:169-76

[154]. Kureshi AK, Dziasko M, Funderburgh JL, Daniels JT. (2015) Human corneal stromal stem cells supportlimbal epithelial cells cultured on RAFT tissue equivalents. Sci Rep. 5:16186.

[155].Sidney LE, Branch MJ, Dua HS, Hopkinson A. (2015) Effect of culture medium on propagation and phenotype of corneal stroma-derived stem cells. Cytotherapy. 17(12):1706-22.

[156]. Dziasko MA, Armer HE, Levis HJ, Shortt AJ, Tuft S, Daniels JT. (2014) Localisation of epithelial cells capable of holoclone formation in vitro and direct interaction with stromal cells in the human crypt. PLoS One. 9(4):e94283.

[157]. Tsai RJ, Tsai RY.( 2014) From stem cell niche environments to engineering of corneal epithelium tissue. Jpn J Ophthalmol. 58(2):111-9.

[158].Lim IJ, Phan TT. (2014) Epithelial and mesenchymal stem cells from the umbilical cord lining membrane. Cell Transplant. 23(4-5):497-503.

[159]. Miyashita H, Yokoo S, Yoshida S, Kawakita T, Yamagami S, et al. (2013) Long-term maintenance of limbal epithelial progenitor cells using rho kinase inhibitor and keratinocyte growth factor. Stem Cells Transl Med. 2(10):758-65.

[160].Levis HJ, Massie I, Dziasko MA, Kaasi A, Daniels JT. (2013) Rapid tissue engineering of biomimetic human corneal limbal crypts with 3D niche architecture. Biomaterials. 34(35):8860-8.

[161]. Brown KD, Low S, Mariappan I, Abberton KM, Short R, et al. (2014) Plasma polymer-coated contact lenses for the culture and transfer of corneal epithelial cells in the treatment of limbal stem cell deficiency. Tissue Eng Part A. 20(3-4):646-55.

[162].KadarT, HorwitzV, SaharR, Cohen M, Cohen L, et al.(2011) Delayed loss of corneal epithelial stem cells in a chemical injury model associated with limbal stem cell deficiency in rabbits. Curr Eye Res. 36(12):1098-107.

[163]. Echevarria TJ, Di Girolamo N (2011) Tissue-regenerating, vision-restoring corneal epithelial stem cells. Stem Cell Rev. 7(2):256-68.

[164]. Ricardo JR, Gomes JA. (2010) Use of stem cells cultured ex vivo for ocular surface reconstruction. Arq Bras Oftalmol. 73(6): 541-7.

[165]. Bobba S, Chow S, Watson S, Di Girolamo N. ( 2015) Clinical outcomes of xeno-free expansion and transplantation of autologous ocular surface epithelial stem cells via contact lens delivery: a prospective case series. Stem Cell Res Ther. 12;6:23.

[166]. Meller D, Fuchsluger T, Pauklin M, Steuhl KP. (2009) Ocular surface reconstruction in graft-versus-host disease with HLA-identical living-related allogeneic cultivated limbal epithelium after hematopoietic stem cell transplantation from the same donor. Cornea. 28(2):233-6.

[167]. Dobrowolski D, Wylegala E, Orzechowska-Wylegala B, Wowra B, Wróblewska-Czajka E. (2011) Application of autologous cultivated corneal epithelium for corneal limbal stemcell insufficiency--short-term results. Klin Oczna. 113(10-12):346-51. 
[168]. Omoto M, Shimmura S, Hatou S, Ichihashi Y, Kawakita T, et al. (2010) Simultaneous deep anterior lamellar keratoplasty and limbal allograft in bilateral limbal stem cell deficiency. Jpn J Ophthalmol. 54(6):537-43.

[169]. Basu S, Hertsenberg AJ, Funderburgh ML, Burrow MK, Mann MM, et al. (2014) Human limbal biopsy-derived stromal stem cells prevent corneal scarring. Sci Transl Med. 6(266):266ra172.

[170].Zhang X, Sun H, Li X, Yuan X, Zhang L, et al. (2010) Utilization of human limbal mesenchymal cells as feeder layers for human limbalstem cells cultured on amniotic membrane. J Tissue Eng Regen Med. 4(1):38-44.

[171]. Chan CC, Holland EJ. (2013) Severe limbal stem cell deficiency from contact lens wear: patient clinical features. Am J Ophthalmol. 155(3):544-549. e2.

[172]. Parekh M, Ferrari S, Di Iorio E, Barbaro V, Camposampiero D, et al. (2012) A simplified technique for in situ excision of cornea and evisceration of retinal tissue from human ocular globe. J Vis Exp. (64):e3765.

[173]. Foster LJ, Karsten E. (2012) A chitosan based, laser activated thin film surgical adhesive, 'SurgiLux': preparation and demonstration. J Vis Exp. (68).

[174]. Jeon S, Choi SH, Wolosin JM, Chung SH, Joo CK. (2013) Regeneration of the corneal epithelium with conjunctival epithelial equivalents generated in serum- and feeder-cell-free media. Mol Vis. 19:2542-50

[175]. Rocca CJ, Kreymerman A, Ur SN, Frizzi KE, Naphade S, et al. (2015) Treatment of Inherited Eye Defects by Systemic Hematopoietic Stem Cell Transplantation. Invest Ophthalmol Vis Sci. 56(12):7214-23.

[176]. Wang S, Ghezzi CE, White JD, Kaplan DL (2015) Coculture of dorsal root ganglion neurons and differentiated human cornealstromal stem cells on silk-based scaffolds. J Biomed Mater Res A. 103(10):3339-48.

[177]. Ni A, Wu MJ, Nakanishi Y, Chavala SH. (2013) Facile and efficient reprogramming of ciliary body epithelial cells into induced pluripotent stem cells. Stem Cells Dev. 22(18):2543-50.

[178].Luesma MJ, Gherghiceanu M, Popescu LM. (2013) Telocytes and stem cells in limbus and uvea of mouse eye. J Cell Mol Med. 17(8):1016-24.

[179].Du Y, Roh DS, Funderburgh ML, Mann MM, Marra KG, etal. (2010) Adipose-derived stem cells differentiate to keratocytes in vitro. Mol Vis. 16:2680-9.

[180]. Joyce NC, Harris DL, Markov V, Zhang Z, Saitta B. (2012) Potential of human umbilical cord blood mesenchymal stem cells to heal damaged corneal endothelium. Mol Vis. 18:547-64.

[181]. Bray LJ, Heazlewood CF, Munster DJ, Hutmacher DW, Atkinson K, Harkin DG. (2014) Immunosuppressive properties of mesenchymal stromal cell cultures derived from the limbus of human and rabbit corneas. Cytotherapy. 16(1):64-73.

[182].Aoki H, Hara A, Niwa M, Motohashi T, Suzuki T, et al. (2008) Transplantation of cells from eye-like structures differentiated from embryonic stem cells in vitro and in vivo regeneration of retinal ganglion-like cells. Graefes Arch Clin Exp Ophthalmol. 246(2):255-65.

[183]. Hayashi R, Ishikawa Y, Ito M, Kageyama T, Takashiba K, etal. (2012) Generation of corneal epithelial cells from induced pluripotent stem cells derived from human dermal fibroblast and corneal limbal epithelium. PLoS One. 7(9):e45435.

[184]. Yao L, Li ZR, Su WR, Li YP, Lin ML, etal. (2012) Role of mesenchymal stem cells on cornea wound healing induced by acute alkali burn. PLoS One. 7(2):e30842

[185]. Garfias Y, Nieves-Hernandez J, Garcia-Mejia M, Estrada-Reyes C, JimenezMartinez MC. (2012) Stem cells isolated from the human stromal limbus possess immunosuppressant properties. Mol Vis. 18:2087-95.

[186].Bray LJ, Heazlewood CF, Atkinson K, Hutmacher DW, Harkin DG. ( 2012) Evaluation of methods for cultivating limbal mesenchymal stromal cells. Cytotherapy. 14(8):936-47.

[187]. Omoto M, Katikireddy KR, Rezazadeh A, Dohlman TH, Chauhan SK. (2014) Mesenchymal stem cells home to inflamed ocular surface and suppress allosensitization in corneal transplantation. Invest Ophthalmol Vis Sci. 55(10):6631-8.

[188]. Lan Y, Kodati S, Lee HS, Omoto M, Jin Y, etal. (2012) Kinetics and function of mesenchymal stem cells in corneal injury. Invest Ophthalmol Vis Sci. 53(7):3638-44

[189].Lin J, Yoon KC, Zhang L, Su Z, Lu R, etal. (2012) A native-like corneal construct using donor corneal stroma for tissue engineering. PLoS One. 7(11):e49571.

[190].Li GG, Chen SY, Xie HT, Zhu YT, Tseng SC. (2012) Angiogenesis potential of human limbal stromal niche cells. Invest Ophthalmol Vis Sci. 53(7):3357-67.

[191].]Oh JY, Kim MK, Ko JH, Lee HJ, Lee JH, et al. (2009) Rat allogeneic mesenchymal stem cells did not prolong the survival of cornealxenograft in a pig-to-rat model. Vet Ophthalmol. 1:35-40.

[192]. Lee RH, Yu JM, Foskett AM, Peltier G, Reneau JC, et al. (2014) TSG-6 as a biomarker to predict efficacy of human mesenchymal stem/progenitorcells (hMSCs) in modulating sterile inflammation in vivo. Proc Natl Acad Sci U
S A. 111(47):16766-71.

[193]. Qi X, Wang J, Sun D, Zhou Q, Xie L. (2014) Postoperative changes in amniotic membrane as a carrier for allogeneic cultured limbal epithelial transplantation. Am J Ophthalmol. 158(6):1192-1198.

[194]. Sati A, Basu S, Sangwan VS, Vemuganti GK (2015) Correlation between the histological features of corneal surface pannus following ocular surface burns and the final outcome of cultivated limbal epithelial transplantation. Br J Ophthalmol. 99(4):477-81.

[195]. Nakatsu MN, González S, Mei H, Deng SX (2014) Human limbal mesenchymal cells support the growth of human corneal epithelialstem/progenitor cells. Invest Ophthalmol Vis Sci. 55(10):6953-9.

[196]. Rahimzadeh A, Tabatabaei Mirakabad FS, Movassaghpour A, Shamsasenjan K, Kariminekoo S, et al. (2014) Biotechnological and biomedical applications of mesenchymal stem cells as a therapeutic system. Artif Cells Nanomed Biotechnol. 1-12.

[197]. Kureshi AK, Funderburgh JL, Daniels JT (2014) Human corneal stromal stem cells exhibit survival capacity following isolation from stored organculture corneas. Invest Ophthalmol Vis Sci. 55(11):7583-8.

[198]. Gage PJ, Kuang C, Zacharias AL (2014) The homeodomain transcription factor PITX2 is required forspecifying correct cell fates and establishing angiogenic privilege in the developing cornea. Dev Dyn. 243(11):1391-400.

[199]. Reinshagen H, Auw-Haedrich C, Sorg RV, Boehringer D, Eberwein P, etal. (2011) Corneal surface reconstruction using adult mesenchymal stem cells in experimental limbal stem cell deficiency in rabbits. Acta Ophthalmol. 89(8):741-8.

[200]. Wen L, Zhang C, Nong Y, Yao Q, Song Z. (2013) Mild electrical pulse current stimulation upregulates S100A4 and promotes cardiogenesis in MSC and cardiac myocytes coculture monolayer. Cell Biochem Biophys. 65(1):43-55.

[201]. PanF, YaoYF. (2011) Research progress on proliferative property and capacity of human cornealendothelium. Zhejiang Da Xue Xue Bao Yi Xue Ban. 40(1):94-100.

[202]. Ghoubay-Benallaoua D, Basli E, Goldschmidt P, Pecha F, Chaumeil C, et al. (2011) Human epithelial cell cultures from superficial limbal explants. Mol Vis. 17:341-54

[203].XieHT, ChenSY, LiGG, TsengSC.(2011) Limbalepithelial stem/progenito cells attract stromal niche cells by SDF-1/CXCR4 signaling to prevent differentiation. Stem Cells. 29(11):1874-85.

[204]. Chen SY, Hayashida Y, Chen MY, Xie HT, Tseng SC. (2011) A new isolation method of human limbal progenitor cells by maintaining close association with their niche cells. Tissue Eng Part C Methods. 17(5):537-48.

[205]. Choi JJ, Ting CT, Trogrlic L, Milevski SV, Familari M, etal. (2014) A role for smoothened during murine lens and cornea development. PLoS One. 9(9):e108037.

[206]. Notara M, Shortt AJ, O'Callaghan AR, Daniels JT. (2013) The impact of age on the physical and cellular properties of the human limbalstem cell niche. Age (Dordr). 35(2):289-300.

[207]. Jiang TS, Cai L, Ji WY, Hui YN, Wang YS, etal. (2010) Reconstruction of the corneal epithelium with induced marrow mesenchymalstem cells in rats. Mol Vis. 16:1304-16.

208].Skeens HM, Brooks BP, Holland EJ. (2011) Congenital aniridia variant: minimally abnormal irides with severe limbal stem cell deficiency. Ophthalmology. 118(7):1260-4.

[209]. Pascual G, Montes MA, Pérez-Rico C, Pérez-Kohler B, Bellón JM, et al. (2010) Expression of embryonic markers in pterygium derived mesenchymal cells. Arch Soc Esp Oftalmol. 85(12):400-4.

[210]. Jorgensen C, Deschaseaux F, Planat-Benard V, Gabison E. (2011) Mesenchymal stem cells: A therapeutic update. Med Sci (Paris). 27(3):275-84.

[211]. Miyamoto T, Sumioka T, Saika S. (2010) Endothelial mesenchymal transition: a therapeutic target in retrocorneal membrane. Cornea. Suppl 1:S52-6.

[212]. Ainscough SL, Linn ML, Barnard Z, Schwab IR, Harkin DG. (2011) Effects of fibroblast origin and phenotype on the proliferative potential of limbal epithelial progenitor cells. Exp Eye Res. 92(1):10-9.

[213]. Chang YJ, Hwang SM, Tseng CP, Cheng FC, Huang SH, et al. (2010) Isolation of mesenchymal stem cells with neurogenic potential from the mesoderm of the amniotic membrane. Cells Tissues Organs. 192(2):93-105.

[214]. Watson SL, Marcal H, Sarris M, Di Girolamo N, Coroneo MT, etal. (2010) The effect of mesenchymal stem cell conditioned media on corneal stromalfibroblast wound healing activities. Br J Ophthalmol. 94(8): 1067-73.

[215]. Alió del Barrio JL, Chiesa M, Gallego Ferrer G, Garagorri N, Briz N, Fernandez-Delgado J, et al. (2015) Biointegration of corneal macroporous membranes based on poly(ethyl acrylate) copolymers in an experimental animal model. J Biomed Mater Res A. 103(3): 1106-18.

[216]. Jia Z, Jiao C, Zhao S, Li X, Ren X, et al.(2012) Immunomodulatory effects of mesenchymal stem cells in a rat corneal allograft rejection model. Exp Eye Res. 102:44-9.

[217]. Pecorella I, Appolloni R, Tiezzi A, Plateroti P, Plateroti R. (2013) Histologi- 
cal findings in a failed corneal riboflavin-UVA collagen cross-linking performed for progressive keratoconus. Cornea. 32(2):191-5.

[218].Zhang XM, Li XR. (2012) Potential applications of mesenchymal stem cells in ocular diseases. Zhonghua Yan Ke Za Zhi. 48(10):956-60.

[219].Seo MS, Park SB, Kim HS, Kang JG, Chae JS, etal.( 2013) Isolation and characterization of equine amniotic membrane-derived mesenchymal stem cells. J Vet Sci. 14(2):151-9.

[220]. De Miguel MP, Alio JL, Arnalich-Montiel F, Fuentes-Julian S, de BenitoLlopis L, et al. (2010) Cornea and ocular surface treatment. Curr Stem Cell Res Ther. 5(2):195-204.

[221]. Qi X, Xie L, Cheng J, Zhai H, Zhou Q. (2013) Characteristics of immune rejection after allogeneic cultivated limbal epithelial transplantation. Ophthalmology. 120(5):931-6.

[222].Li GG, Zhu YT, Xie HT, Chen SY, Tseng SC. (2012) Mesenchymal stem cells derived from human limbal niche cells. Invest Ophthalmol Vis Sci. 53(9):5686-97.

[223]. Ueno H, Ferrari G, Hattori T, Saban DR, Katikireddy KR, et al. (2012) Dependence of corneal stem/progenitor cells on ocular surface innervation. Invest Ophthalmol Vis Sci. 53(2):867-72.

[224]. Martínez-Conesa EM, Espel E, Reina M, Casaroli-Marano RP. (2012) Characterization of ocular surface epithelial and progenitor cell markers in human adipose stromal cells derived from lipoaspirates. Invest Ophthalmol Vis Sci. 53(1):513-20.

[225]. Kawakita T. (2011) Improvement in the method of cultivated corneal epithelial sheet generation. Nippon Ganka Gakkai Zasshi. 115(11):1007-14.

[226]. Chen X, Thomson H, Hossain P, Lotery A. (2012) Characterization of mouse limbal neurosphere cells: a potential cell source of functional neurons. Br J Ophthalmol. 96(11):1431-7.

[227]. Oh JY, Lee RH, Yu JM, Ko JH, Lee HJ, et al. (2012) Intravenous mesenchymal stem cells prevented rejection of allogeneic corneal transplants by aborting the early inflammatory response. Mol Ther. 20(11): 2143-52.

[228].Sapin V, Souteyrand G, Bonnin N, Gallot D, Blanchon L, et al. (2011) Therapeutic use of amniotic membranes and their derivate cells. Gynecol Obstet Fertil. 39(6):388-90.

[229]. Satake Y, Higa K, Tsubota K, Shimazaki J.( 2011) Long-term outcome of cultivated oral mucosal epithelial sheet transplantation in treatment of total limbal stem cell deficiency. Ophthalmology. 118(8):1524-30.

[230].Tan EK, He H, Tseng SC. (2011) Epidermal differentiation and loss of clonal growth potential of human limbal basal epithelial progenitor cells during intrastromal invasion. Invest Ophthalmol Vis Sci. 52 (7) : 4534-45.

[231]. Criscimanna A, Zito G, Taddeo A, Richiusa P, Pitrone M, et al.(2012) In vitro generation of pancreatic endocrine cells from human adult fibroblastlike limbal stem cells. Cell Transplant. 21(1):73-90.

[232]. Karamichos D, Funderburgh ML, Hutcheon AE, Zieske JD, Du Y, et al. (2014) A role for topographic cues in the organization of collagenous matrix by cornealfibroblasts and stem cells. PLoS One. 9(1):e86260.

[233]. Wu J, Du Y, Mann MM, Funderburgh JL, Wagner WR. (2014) Corneal stromal stem cells versus corneal fibroblasts in generating structurally appropriate corneal stromal tissue. Exp Eye Res. 120:71-81.

[234]. Takahashi M, Haruta M. (2006) Derivation and characterization of lentoid bodies and retinal pigment epithelial cells from monkey embryonic stem cells in vitro. Methods Mol Biol. 330:417-29.

[235]. Branch MJ, Hashmani K, Dhillon P, Jones DR, Dua HS, et al.( 2012) Mesenchymal stem cells in the human corneal limbal stroma. Invest Ophthalmol Vis Sci. 53(9):5109-16.

[236]. Hu N, Zhang YY, Gu HW, Guan HJ. (2012) Effects of bone marrow mesenchymal stem cells on cell proliferation and growth factor expression of limbal epithelial cells in vitro. Ophthalmic Res. 48(2):82-88.

[237].Liu W, Zhang Y, Xu G, Qian J, Jiang C, et al.( 2011) Optical coherence tomography for evaluation of photodynamic therapy in symptomatic circumscribed choroidal hemangioma. Retina. 31(2):336-43.

[238]. Roddy GW, Oh JY, Lee RH, Bartosh TJ, Ylostalo J, et al. (2011) Action at a distance: systemically administered adult stem/progenitor cells(MSCs) reduce inflammatory damage to the cornea without engraftment and primarily by secretion of TNF- $\alpha$ stimulated gene/protein 6 . Stem Cells.
29(10):1572-9.

[239]. Ittner LM, Wurdak H, Schwerdtfeger K, Kunz T, Ille F, et al. (2005) Compound developmental eye disorders following inactivation of TGFbeta signaling in neural-crest stem cells. J Biol.;4(3):11.

[240].Lord-Grignon J, Abdouh M, Bernier G. (2006) Identification of genes expressed in retinal progenitor/stem cell colonies isolated from the ocular ciliary body of adult mice. Gene Expr Patterns. 6(8):992-9.

[241]. Koulikovska M, Rafat M, Petrovski G, Veréb Z, Akhtar S, et al. (2015) Enhanced regeneration of corneal tissue via a bioengineered collagen construct implanted by a nondisruptive surgical technique. Tissue Eng Part A. 21(5-6):1116-30

[242]. Chae JJ, Ambrose WM, Espinoza FA, Mulreany DG, Ng S, et al. (2015) Regeneration of corneal epithelium utilizing a collagen vitrigel membrane in rabbit models for corneal stromal wound and limbal stem cell deficiency. Acta Ophthalmol. 93(1):e57-66.

[243].Zajicova A, Pokorna K, Lencova A, Krulova M, Svobodova E, et al. (2010) Treatment of ocular surface injuries by limbal and mesenchymal stem cells growing on nanofiber scaffolds. Cell Transplant. 19(10):1281-90.

[244]. Ma XY, Bao HJ, Cui L, Zou J (2013) The graft of autologous adiposederived stem cells in the corneal stromal after mechanic damage. PLoS One. 8(10):e76103.

[245]. Hou GH, Ye N, Wu J, Xu JT, Shi WJ, et al. (2010) Preliminary study on human bone marrow mesenchymal stem cellsdifferentiation into epitheliallike cells. Zhonghua Yan Ke Za Zhi. 46(8):719-24.

[246]. Arjamaa O (2012) Corneal reconstruction by stem cells and bioengineering. Clin Ophthalmol. 6:1407-9.

[247]. Barbaro V, Ferrari S, Fasolo A, Ponzin D, Di Iorio E (2009) Reconstruction of a human hemicornea through natural scaffolds compatible with the growth of corneal epithelial stem cells and stromal keratocytes. Mol Vis. 15:2084-93.

[248].Chaurasia SS, Perera PR, Poh R, Lim RR, Wong TT, et al. (2013) Hevin plays a pivotal role in corneal wound healing. PLoS One. 8(11): e81544.

[249]. Gomes JA, Geraldes Monteiro B, Melo GB, Smith RL, Cavenaghi Pereira da Silva M, etal. (2010) Corneal reconstruction with tissue-engineered cell sheets composed of human immature dental pulp stem cells. Invest Ophthalmol Vis Sci. 51(3):1408-14.

[250]. Rohaina CM, Then KY, Ng AM, Wan Abdul Halim WH, Zahidin AZ, et al. (2014) Reconstruction of limbal stem cell deficient corneal surface with induced human bone marrow mesenchymal stem cells on amniotic membrane. Transl Res. 163(3):200-10.

[251].Feng Y, Borrelli M, Reichl S, Schrader S, Geerling G. (2014) Review of alternative carrier materials for ocular surface reconstruction. Curr Eye Res. 39(6):541-52

[252].Lee SH, Kim KW, Kim MK, Chun YS, Kim JC. (2014) Evaluation of stem cell components in retrocorneal membranes. J Korean Med Sci. 29(6): 84651

[253]. Sharma SM, Fuchsluger T, Ahmad S, Katikireddy KR, Armant M, etal (2012) Comparative analysis of human-derived feeder layers with 3T3 fibroblasts for the ex vivo expansion of human limbal and oral epithelium. Stem Cell Rev. 8(3):696-705.

[254]. Cejkova J, Trosan P, Cejka C, Lencova A, Zajicova A, et al. (2013) Suppression of alkali-induced oxidative injury in the cornea by mesenchymal stem cells growing on nanofiber scaffolds and transferred onto the damaged corneal surface. Exp Eye Res. 116:312-23.

[255]. Sejpal K, Yu F, Aldave AJ. (2011) The Boston keratoprosthesis in the management of corneal limbal stem cell deficiency. Cornea. 30(11):1187-94.

[256].Zakaria N, Van Marck V, Koppen C, Berneman Z, Tassignon MJ (2012) Lymphangiogenesis may play a role in cultivated limbal stem cell transplant rejection. Ocul Immunol Inflamm. 20(5): 381-3.

[257]. Hägglund AC, Dahl L, Carlsson L. (2011) Lhx2 is required for patterning and expansion of a distinct progenitor cell population committed to eye development. PLoS One. 6(8): e23387. 